\title{
Input-Trade Liberalization and the Demand for Managers: Evidence from India*
}

\author{
Pavel Chakraborty ${ }^{\dagger}$ \\ Lancaster University
}

\author{
Ohad Raveh ${ }^{\ddagger}$ \\ Hebrew University of Jerusalem
}

January 2018

\begin{abstract}
Can input-trade liberalization increase the demand for managers? Imported inputs are an important source of technology inflows. Previous research on the implications of imported inputs overlooked their potential effect on the demand for managing the new incoming knowledge. Adopting the case of India, this paper presents a first empirical attempt to fill this gap. Using detailed firm-level data that uniquely distinguishes between the compensations of managers and non-managers, and exploiting the exogenous nature of India's Eight-Plan trade reform, we investigate the potential causal link between input-trade liberalization and the demand for managers relative to non-managers. We find that a decrease in input tariffs increases the relative demand for managers, primarily in domestic firms that use the imported inputs to produce intermediate goods. Specifically, a $10 \%$ drop in input tariffs induces, on average, a $1-1.5 \%$ increase in the compensation share of managers, manifested via increases in both their number as well as average wages and bonuses. These patterns are: (i) observed across the firms' size distribution; (ii) applicable for both exporting and non-exporting firms; (iii) stronger in familyrun firms that operate under flexible labor market regulations; (iv) relatively more dominant in the short-run. In addition, we show that unlike changes in input tariffs, import competition does not affect the relative demand for managers.
\end{abstract}

JEL classifications: F66, F14, M12

Keywords: Input-trade liberalization, input tariffs, demand for managers, firm organization

\footnotetext{
${ }^{*}$ The paper circulated previously with the title "Trade Liberalization, Intermediate Inputs, and the Demand for Managers: Evidence from India". We thank Himanshu, Richard Baldwin, Subhayu Bandyopadhyay, Nicholas Bloom, Dave Donaldson, Carsten Eckel, Joseph Flavian Gomes, Beata Javorcik, Amit Khandelwal, Krisztina Kis-Katos, Dirk Krueger, Manoj Pant, Saikat Sinha Roy, and Anthony Venables, for their detailed and insightful comments. We also thank seminar participants at BI Norwegian Business School, Geneva Trade and Development Workshop, Hebrew University of Jerusalem, Indira Gandhi Institute of Development Research at Mumbai, Jadavpur University Kolkata, Jawaharlal Nehru University, National Council of Applied Economic Research at New Delhi, Norwegian School of Economics and Business Administration at Bergen, South Asian University, University of Gottingen, University of Oxford, World Bank - Trade and Competitiveness Department, the 2015 European Trade Study Group Conference, the 2015 Nordic Conference on Development Economics, and the 2016 XXVIth Annual Conference on Contemporary issues in Development, for the helpful discussions. We are greatly indebted to Reshad Ahsan, Hunt Allcott, and Sangeeta Ghosh for generously sharing data on various measures of the Indian manufacturing sector.

${ }^{\dagger}$ Department of Economics, Management School, Lancaster University, Lancaster, UK. Email: p.chakraborty1@lancaster.ac.uk

${ }^{\ddagger}$ Department of Environmental Economics and Management, Hebrew University of Jerusalem, Rehovot, Israel. Email: ohad.raveh@mail.huji.ac.il
} 


\section{Introduction}

Can input-trade liberalization increase the demand for managers? Imported inputs make an important source of technology inflows, especially in developing economies which import significant portions of their equipment. ${ }^{1}$ These, in turn, may lead to changes in firms' production technologies, requiring labor adjustments in terms of training, and problem solving. Previous research show that access to cheaper and previously unavailable inputs have important implications for productivity and output. ${ }^{2}$ This literature, however, overlooked the potential effects of the imported inputs on the demand for managing the new incoming knowledge. This may be especially prominent in light of the recently emerging theoretical literature on the effects of trade liberalization on firm managerial practices, quality, and hierarchical structure, ${ }^{3}$ and its importance to productivity and performance, ${ }^{4}$ including in developing economies. ${ }^{5}$ Examining whether imported inputs are associated with managerial incentives may, thus, shed light on first-order issues such as the impact of trade policies on firms' growth and productivity. ${ }^{6}$ Adopting the case of India, this paper makes a first empirical attempt to fill this gap.

Using a rich data set of Indian manufacturing firms that uniquely distinguishes between the compensations of managers and non-managers, ${ }^{7}$ we explore the impact of plausibly exogenous changes in input tariffs on the demand for managers relative to non-managers. The emphasis on the relative demand of managers is central in our analysis. Imported-inputs-driven changes in the production process, via the new incoming technologies, may affect the demand for both managers and non-managers. For instance, considering this along the lines of Caliendo and Rossi-Hansberg (2012) and Garicano (2000), firms that face a more complex production technology may upgrade the skills of their production workers (non-managers), yet may otherwise economize on the problem solving process by increasing the quality and number of specialist problem solvers (managers),

\footnotetext{
${ }^{1}$ These patterns are documented in various studies including Caselli and Wilson (2004), Eaton and Kortum (2001), and Raveh and Reshef (2016). This was especially prominent during the 1990s, a period relevant to our study, during which several developing economies imported the vast majority of their capital equipment. Importantly, these imports were made from a small number of industrialized economies.

${ }^{2}$ See Amiti and Konings (2007), Bas (2012), Bas, Johansson, Murtin, and Nicoletti (2016), Bas and Strauss-Kahn (2014), Bas and Strauss-Kahn (2015), Goldberg, Khandelwal, Pavcnik, and Topalova (2010), Halpern, Koren, and Szeidl (2015), Kasahara and Lapham (2013), and Topalova and Khandelwal (2011), among others.

${ }^{3}$ Models that present associations between trade liberalization and firm organization include Caliendo and RossiHansberg (2012), Ma (2015), Marin and Verdier (2003), Marin and Verdier (2008), and Marin and Verdier (2014).

${ }^{4}$ See e.g. Bloom, Brynjolfsson, Foster, Jarmin, Saporta-Eksten, and Van Reenen (2013). We discuss this literature in more detail in a later sub-section.

${ }^{5}$ Bloom, Eifert, Mahajan, McKenzie, and Roberts (2013) point at the prominence of this in the case of India.

${ }^{6}$ See Goldberg and Pavcnik (2016) on the need for analyses that examine the effects of trade policies on firm and individual outcomes.

${ }^{7}$ We define managers as any workers who manage at least one other worker (or who is the sole worker in the firm), with non-managers accounting for the remaining balance. We discuss this in further detail in the empirical part.
} 
depending on which option minimizes their costs. Hence, approaching this empirically requires examining the complementarity (or substitutability) of imported inputs and managers relative to that of imported inputs and non-managers.

We start by presenting the link between trade and the relative demand for managers in our sample of Indian firms, for the period of 1990-2006. This is plotted in Figure 1. ${ }^{8}$ Both measures have been increasing steadily throughout the period, exhibiting a correlation of 0.85 . The surge in trade is a consequence of the Indian 1990s trade reform which we discuss further below. The increase in the compensation share of managers is what we aim to investigate. ${ }^{9}$ We seek to understand whether there is indeed a systematic association between the two. Figure 2 points at a possible direction. Dividing the relative demand measure to importing and non-importing firms indicates that the surge is almost an exclusive feature of the former types. This intrigues undertaking a more careful examination of the association between imports and the relative demand for managers.

To do so, we first motivate the analysis via a simple analytical framework, along the lines of Berman, Bound, and Griliches (1994). This yields a reduced form equation that links between imports and the relative demand for managers, which we follow in the empirical analysis. In a preliminary examination, testing trade measures directly via conditional correlations, we find that consistent with Figure 2, it is only imports -and more specifically those of intermediate inputs- that are positively associated with the relative demand for managers. This then refutes the possibility of observing a simple administrative relabeling (an option we elaborate on later), and paves the way to considering tariffs in an attempt to provide causal inferences.

To establish a causal link, we exploit a quasi-natural experiment, India's Eight-Plan trade reform. The details of this reform, and its merits in the context of our case, are outlined separately in the following section. The key point is that this reform provides plausibly exogenous changes in industry-level input and output tariffs, with ample cross-industry variation, which we use as the basis of our identification strategy. ${ }^{10}$ We find a remarkably persistent and economically meaningful negative effect that, consistent with the findings in the initial analysis, is entirely driven by input tariffs. The relative dominance of input, over output, tariffs suggests that this effect is manifested

\footnotetext{
${ }^{8}$ The figure presents yearly average (over all firms), 1990-2006, of the share of total trade in gross value added and the share of managerial compensation in total labor compensation. We proxy for the relative demand for managers using the latter. We discuss both measures in more detail in the empirical part.

${ }^{9}$ Notably, the observed steep increase in managerial compensation over the given period is not a unique feature of the Indian economy, and is also observed elsewhere. Data from S\&P Capital IQ's Compustat ExecuComp Database indicates that the median annual compensation of CEOs of firms included in the S\&P 500 Index grew from approximately $3 \$$ million in 1992 to almost $10 \$$ million in 2006 (in 2011 prices), hence increasing by a factor of three.

${ }^{10} \mathrm{By}$ which we, in effect, follow the empirical methodology, and data sources of previous studies that examined the effects of this trade reform on the Indian economy, including Ahsan (2013), Ahsan and Mitra (2014), Bas and Berthou (2017), De Loecker, Goldberg, Khandelwal, and Pavcnik (2016), Goldberg, Khandelwal, Pavcnik, and Topalova (2010), Hasan, Mitra, Ranjan, and Ahsan (2012), and Topalova and Khandelwal (2011).
} 
via changes in the production side rather than through a product market (import) competition. In terms of magnitude, our benchmark estimates indicate that a $10 \%$ decrease in input tariffs increases the relative demand for managers by approximately $1-1.5 \%$. This effect is robust to considering various controls, specifications, and estimation techniques. Specifically, it is not an outcome of industry-specific trends, such as for instance a delicensing reform (outlined in more detail later), and is robust to potential associations between managers and: skill, capital intensity, productivity, export tariffs, and management technology.

Examining the separate components of the relative demand measure we find that this effect is triggered by changes in managers' compensation, rather than by that of non-managers. This, in turn, suggests that it is not an outcome of outsourcing or other schemes that may lead to major layoffs of non-managers, such as for instance systematic cross-industry differences in firms' exit rates. Decomposing the managers' compensation into its wages and bonuses components, we find that both of them increase as a response to a decrease in input tariffs. Similarly, the number of executives increase, as well as the average (per-executive) wages and bonuses. These patterns are driven primarily by the input-importing domestically owned firms that produce intermediate goods. Additional tests indicate that these patterns are: (i) observed across the firms' size distribution; (ii) applicable in both exporting and non-exporting firms; (iii) stronger in family-run firms that operate under flexible labor market regulations; (iv) relatively more dominant in the short-run.

The analysis ends with a discussion of results. We begin this discussion by summarizing the main findings, and highlighting their contribution to understanding some of the key questions related to the impact of trade policies. Thereafter, we consider a conceptual framework that may shed light on the potential underlying mechanisms at work. In particular, drawing on the results of previous related theoretical and empirical research, we interpret the main findings to be an outcome of changes in firms' organization of knowledge, triggered by the new technologies embedded in the incoming inputs.

The paper contributes in addition to two strands of literature. First is the empirical literature on trade liberalization and firm organization, for which the contribution is threefold. First, previous empirical studies that examined the trade-organization nexus were based on case studies of developed economies. ${ }^{11}$ Through the case of India, this paper makes a first attempt to study aspects of this nexus in a developing economy, emphasizing its potential distinctive features in this

\footnotetext{
${ }^{11}$ Empirical evidence has been based on data from: Austria and Germany (Marin (2009), and Marin and Verdier (2014)), France (Caliendo, Monte, and Rossi-Hansberg (2015)), Portugal (Fernandes, Ferreira, and Winters (2014)), Norway and Sweden (Oxelheim and Randy (2005)), U.K. (Acemoglu, Aghion, Lelarge, and Van Reenen (2007)), and the U.S. (Carpenter and Sanders (1998), Cunat and Guadalupe (2009), Friedrich (2016), Guadalupe and Wulf (2010), Ma (2015), Marin and Verdier (2008), and Keller and Olney (2017)) - all of which belong to the group of highly developed countries.
} 
context. This connects to the second point. Previous research emphasized the role of product market competition in affecting firm organization. ${ }^{12}$ Conversely, we show that in a developing economy, where imported inputs play a central role in absorbing new technologies, input-trade liberalization may be more prominent than import competition. Third, previous studies examined components related primarily to the managerial side, such as wages and bonuses. Very little attention, however, has been given to the inclusion of the non-managers' side to consider relative terms and within-firm inequality. ${ }^{13}$ Our analysis examines both concurrently, providing interpretations in both absolute and relative terms.

Second is the literature on trade liberalization and the demand for skill in developing economies. Neoclassical trade theory, via the Stolper-Samuelson theorem, predicts that trade liberalization increases demand in the abundant factor, which is expected to translate to increased relative demand for low-skill labor in developing economies. Several studies, however, document an increase in the skill premium in some developing economies, especially during the 1980s and 1990s (Goldberg and Pavcnik (2007)). Various explanations have been offered, including trade-induced skill-biased technical change (Acemoglu (2003), and Zeira (2007)), capital-skill complementarity (Burstein, Cravino, and Vogel (2013), and Parro (2013)), credit constraints (Bonfatti and Ghatak (2013)), import composition (Raveh and Reshef (2016)), improved exports (Zhu and Trefler (2005)), and quality upgrading (Verhoogen (2008)). We show that our main result is not an outcome of an increase in the demand for skill; nonetheless, since our analysis focuses on relative terms, and managers are included in the standard definition of the skilled group, ${ }^{14}$ this paper points at a new potential contributing factor: imported inputs that increase the relative demand for managers.

The paper is structured as follows. Section 2 outlines the details of the firm-level data. Section 3 undertakes the main exercise, examining the effects of input-trade liberalization on the relative demand for managers. Section 4 concludes.

\section{Firm-Level Data}

We examine firms in the Indian manufacturing sector. The firm-level analysis is primarily based on the PROWESS database, constructed by the Centre for Monitoring the Indian Economy (CMIE),

\footnotetext{
${ }^{12}$ Some examples include Cunat and Guadalupe (2009), Marin and Verdier (2008), Bloom, Draca, and Van Reenen (2016), and Bloom, Sadun, and Van Reenen (2010).

${ }^{13}$ Two exceptions are Friedrich (2016) and Ma (2015). The former examines the effect of trade barriers on withinfirm wage inequality via changes in firm hierarchies, using a sample of Danish firms. The latter studies the impact of globalization on executives' income shares in U.S. firms. In contrast, we examine the effects of input-trade liberalization on the compensation share of managers, within the context of a developing economy.

${ }^{14}$ Most of the said papers adopt a skill division of production and non-production workers, where the managers group is included in the latter.
} 
an Indian government sponsored agency. We outline the features of this dataset in detail in this section.

The PROWESS database contains annual-based information, covering the period 1990-2011, on approximately 27,400 publicly listed companies, all within the organized sector, of which almost 11,500 are in the manufacturing sector. ${ }^{15}$ It reports direct measures on a vast array of firm-level characteristics including sales, disaggregated trade components, R\&D expenditures, technology transfers, production factors employed, gross value added, assets, ownership, and others which we outline further within the empirical analysis. In addition, it covers both large and small enterprises. Data for the former types are collected from balance sheets, whereas those for the latter ones are based on CMIE's periodic surveys of smaller companies.

PROWESS presents several features that make it particularly appealing for the purposes of our study, and puts it in an advantage compared to other available sources, such as the Indian Annual Survey of Industries (ASI), for instance. First, unlike other sources, the PROWESS data is in effect a panel of firms that enables us to study their behavior over time. Specifically, the (unbalanced) sample covers 8,000 firms, across 108 (4-digit NIC) manufacturing industries that belong to 22 (2-digit NIC) larger ones, ${ }^{16}$ over the period of 1990-2006. ${ }^{17}$ Importantly, it covers the 1990s trade reform, being an essential part of our analysis that we discuss later.

Second, the unique feature of the data set, on which our study is mainly based, is that it disaggregates compensation data to those received by managers and non-managers, with a further disaggregation of compensation to wages and bonuses. ${ }^{18}$ Specifically, the division relates to three categories: non-managers, directors, and executives. The latter two comprise the managers' group. The definition of the former is that they do not manage other employees; conversely, directors (executives) are defined as managers without (with) executive powers. Executives include, for instance, the CEO, CFO, and Chairman, whereas Directors may cover positions such as Divisional Managers. While there is scope for subjective interpretation of this distinction by firms, it does not

\footnotetext{
${ }^{15}$ While placed according to the 4-digit 2008 National Industrial Classification (NIC) level, firms are reclassified to the 2004 level to facilitate matching with the industry-level tariffs. Hence, all industry-level categorization made throughout the paper are based on the 2004 NIC classification.

${ }^{16}$ In terms of composition, approximately $20 \%$ of the firms in the dataset are registered under the Chemical and Pharmaceutical industries, followed by Food Products and Beverages (13.74\%), Textiles (10.99\%) and Basic Metals $(10.46 \%)$.

${ }^{17}$ We limit the analysis to 2006 , which in turn limits the number of firms covered, to avoid potential biases caused by the 2008 financial crisis. Nonetheless, we note that the main results are robust to extending the analysis to 2011.

${ }^{18}$ An additional source that provides similar data is the ExecuComp data set (used for instance in Cunat and Guadalupe (2009), and Keller and Olney (2017)). While its coverage in terms of years and firms is largely similar to that of PROWESS (ExecuComp covers around 3500 firms, over the years 1992-2015), it differs from PROWESS on a number of fronts. First, it pertains to a developed economy, the United States. Second, it does not provide compensation data on non-managers, or non-executive managers. Third, it does not provide firm-level trade measures. Last, its executive compensation data is richer in terms of its available components.
} 
affect our main analysis which considers the aggregate of Executives and Directors. These features enable us to study the demand for managers, relative to non-managers, and its potential sources, over a relatively large period of time.

Importantly, the data set provides ample variation across firms and industries in the compensation characteristics of managers compared to non-managers. For instance, in Figure 3 we plot the average share of managerial compensation in total labor compensation across 2-digit industries for the period of 1990-2006. Going from a low of approximately $0.5 \%$ to a high of around $3.5 \%$, the difference across industries is clearly observed. This is also seen when measuring changes over time. Averaging annual changes over the same period, we observe that while in some industries the average annual rate of change is around $10 \%$, in others it can get higher than $200 \%$. This translates to the firm level, where such variation is even more prominent.

One key related characteristic is that close to $25 \%$ of firms report having no managerial compensation. These firms either have no managerial layer, or their managerial compensation is low. ${ }^{19}$ The former is consistent with the family-oriented Indian firm culture (Bloom, Eifert, Mahajan, McKenzie, and Roberts (2013)). The data, however, support the potential prominence of the latter. To see this, in Table 1 we compare some of the key firm-level measures of firms that report no managerial compensation to those that do. The key differences are in size and technology. Specifically, firms that report having no managerial income produce significantly less output, are less capital intensive, and spend less on R\&D. Conversely, family-owned firms are spread across the firms' size distribution (Bloom, Eifert, Mahajan, McKenzie, and Roberts (2013)). ${ }^{20}$

Last, PROWESS has a relatively wide coverage, accounting for more than $70 \%$ of the economic activity in the organized industrial sector, and 75\% (95\%) of corporate (excise duty) taxes collected by the Indian Government (Goldberg, Khandelwal, Pavcnik, and Topalova (2010)). In terms of trade, it covers approximately 30-35\% of India's total exports and imports activity, presenting a reasonably good aggregate picture on India's trade position. All variables are measured in Millions of Indian Rupees (INR), deflated to 2005 using the industry-specific Wholesale Price Index, ${ }^{21}$ and are outlined in the Appendix. Table 2 presents descriptive statistics for all variables. ${ }^{22}$

\footnotetext{
${ }^{19}$ Notably, compensation values of less than 100,000 Indian Rupees are reported by PROWESS as zero.

${ }^{20}$ In addition, an examination of family-owned firms conducted in a later sub-section provides further support. As will be evident, it is rather the family-owned firms that yield the steepest increase in the compensation share of managers, following input-trade liberalization.

${ }^{21}$ We thank Hunt Allcott for sharing this data, used in Allcott, Collard-Wexler, and O'Connell (2016).

${ }^{22}$ One pattern described in Table 2 deserves further comment. As reported, maximum figures of various Gross Value Added (GVA) normalized measures can reach relatively high values. This is a feature of the definition of GVA (see Appendix), and occurs in cases of high purchases and low sales, such as in initial investments, for instance. All results are robust to omitting observations with GVA-normalized figures higher than one; nonetheless, we maintain the full sample in the main analyses for the purposes of exploiting its full extent.
} 


\subsection{Data quality}

The PROWESS database has been used in various previous similar studies on trade liberalization, ${ }^{23}$ providing some reassurance for its relevance and applicability to the particular issues studied, as well as for its overall reliance. However, to the best of our knowledge we are the first to study its managerial compensation measures in this context. That said, we next discuss two qualityrelated aspects of these measures: accuracy and consistency, as these may take a central role in the empirical analysis.

Starting with accuracy, as mentioned CMIE retrieves most of the compensation data from balance sheets, reported in publicly-available annual reports. To test the accuracy of our measures of interest, we compare the data reported in PROWESS to those reported in the annual reports for a random selection of firms, representing both relatively large and small ones, in the year 2011.

Results appear in the Appendix Tables 12 and 13. In the first (Table 12), we compare between the reported compensation of executives (Columns (1) and (2)) and directors (Columns (3) and (4)). In both cases we observe a strong match between the compensation data reported in PROWESS and those given in the annual reports, with correlations being higher than 0.99. In the second (Table 13), we compare the number of reported executives in each of the sources, with the correlation being 1. Albeit not covering all years, firms, or the entire range of variables, these results provide some affirmation for the accuracy and reliability of the measures used.

Moving to consistency, the analysis implicitly assumes that there is consistency in the definition of managers across firms. However, the said family-oriented nature of Indian firms, and the surveys CMIE uses for smaller firms, may give rise to some subjectivity in that respect. This deserves some comment. First, we note that all firms included in the analysis are listed in the Mumbai Stock Exchange, and hence are subject to the same corporate governance regulations, including the said definitions. This provides a more homogenous, and regulated, environment that mitigates the given concern. Second, as will be evident we show that the main patterns are observed across the firms' size distribution, with constant magnitudes across size-groups, indicating that the main results hold irrespective of firm size. This further mitigates concerns related to sensitivities to CMIE's source and to potential subjectivities.

\footnotetext{
${ }^{23}$ See e.g. Ahsan (2013), Ahsan and Mitra (2014), De Loecker, Goldberg, Khandelwal, and Pavcnik (2016), Goldberg, Khandelwal, Pavcnik, and Topalova (2010), and Topalova and Khandelwal (2011).
} 


\section{Input-trade Liberalization and the Demand for Managers}

We examine the association between input-trade liberalization and the relative demand for managers, using the firm-level data described above. This is done in various steps. First, we present an analytical framework that establishes a reduced form equation that links the two key measures. Second, motivated by the latter, we undertake a preliminary analysis that examines trade measures directly. Third, based on the results of this initial analysis we then investigate the link between changes in input tariffs and the relative demand for managers, to provide a causal interpretation. Last, we summarize the main findings, discuss their merits, and consider possible triggering factors.

\subsection{Analytical framework}

Let us lay out a simple analytical framework to help organize the discussion. Our main focus is on trade liberalization vis-à-vis changes in tariffs. Realizing, however, that by definition tariffs affect imports directly, and for tractability purposes, we link the latter directly to imports within our setting. ${ }^{24}$ We follow the framework set by Berman, Bound, and Griliches (1994), applied to our case. $^{25}$

Suppose a representative firm, within a given industry of a developing economy, ${ }^{26}$ uses three inputs: managers $(m)$, non-managers $(n)$, and imports $(M) .{ }^{27}$ Imports are regarded as inputs because the vast majority of equipment, within the type of economy and period we investigate, is imported (Eaton and Kortum (2001)). The price of imports is determined in international markets, taken as given by local firms. $M$ is, therefore, assumed to be a quasi-fixed factor. Conversely, $m$ and $n$ are variable inputs. Firms operate in a competitive industry, where factor prices are set accordingly, and production exhibits constant returns to scale. Cost minimization then yields the following relationship:

$$
S=\alpha+\beta \ln \left(\frac{w_{m}}{w_{n}}\right)+\gamma \ln \left(\frac{M}{y}\right) .
$$

The compensation share of managers in total labor compensation $\left(\frac{w_{m} m}{c}\right), S$, is affected by the managers to non-managers wage ratio, and the output share of imports. Details on the derivations

\footnotetext{
${ }^{24}$ This follows Cunat and Guadalupe (2009) and Guadalupe and Wulf (2010), for instance, who also maintain a focus on import penetration for investigating related issues.

${ }^{25}$ Other recent studies that adopt this framework for questions related to skill-heterogeneity include Larrain (2015), Michaels, Natraj, and Van Reenen (2014), and Raveh and Reshef (2016).

${ }^{26}$ This links to the empirical part, where albeit examining firm-level data where possible, we primarily take a cross-industry perspective.

${ }^{27}$ The inclusion of three inputs is a simplification. Adding further inputs, or otherwise further disaggregating the ones included, would not change the basic outcome; rather, it would result in having further independent components in the reduced form outcome. We account for that in the empirical analysis, as we include a multitude of controls, including some that are a disaggregation of the core inputs included.
} 
are in Appendix D.

We follow Berman, Bound, and Griliches (1994) and assume that the quality-adjusted price ratio of managers to non-managers does not vary across industries. In such a case it only affects the constant term in case it is dropped, which will be done due to data limitations. Nonetheless, as in Michaels, Natraj, and Van Reenen (2014) we shall add year by industry fixed effects that absorb the relative wage term in case the above assumption is relaxed. We are therefore left with the following outcome:

$$
S=\alpha+\gamma \ln \left(\frac{M}{y}\right) .
$$

Relaxing the assumption of constant returns to scale in technology, as is done in the empirical analysis, requires controlling for output, yielding the following:

$$
S=\alpha+\gamma \ln \left(\frac{M}{y}\right)+\delta \ln (y) .
$$

This empirically testable association links between the output share of imports, and the share of managers' compensation in total labor compensation, regarded as the relative demand for managers.

To comment on its interpretation, suppose that $M$ brings in new technologies that may affect the demand for the other inputs. For instance, as motivated initially, non-managers may receive further training to work with the new technologies, upgrading their skills, whereas managers may increase their span of control in an attempt to economize on the problem solving process that involves adjusting to new technologies. Equation (3) enables testing the relative complementarity (or substitutability) of $M$ to either of the inputs. Specifically, a positive $\gamma$ indicates that $M$ is relatively more complementary to managers, increasing their relative demand. Next, we test this hypothesis using the firm-level data.

\subsection{Preliminary analysis: Trade measures}

We start by estimating the empirical counterpart of Equation (3). While the analytical framework focused on imports, in this preliminary analysis we examine both import and export penetration for completeness, and to better motivate the focus on the former. Hence, we consider the following managers' compensation share equation, for firm $i$, in industry $j$, at time $t$ :

$$
\frac{M \operatorname{comp}}{\operatorname{Tcomp}}_{i, t}=\alpha+\beta \ln \left(\frac{T}{G V A}\right)_{i, t}+\gamma \mathbf{X}_{i, t}+\delta_{i}+\nu_{j} * \eta_{t}+\epsilon_{i, t},
$$

where $M$ comp is the managers' total compensation, Tcomp is total labor compensation, $T$ is total imports or exports, $G V A$ is gross value added, $\mathbf{X}$ is a vector of controls that we specify below, and $\delta, \nu, \eta$ are firm, industry, and time fixed effects, respectively. In effect, this model examines the 
determinants of the relative demand for managers. Specifically, we are interested in understanding the characteristics of $\beta$; namely, the empirical association between normalized imports, or exports, and the relative demand for managers.

Our benchmark setting includes several points. First, as mentioned we examine an annualbased, unbalanced panel over the period of 1990-2006. Second, standard errors are clustered at the firm-level in all cases. Third, on top of the separate fixed effects terms, $\delta_{i}$ and $\eta_{t}$, the specification also includes the interactions of $\nu_{j}$ and $\eta_{t}$. These interaction terms control for various within-year industry trends, such as the industry-year specific delicensing or FDI-liberalization phenomena, ${ }^{28}$ the managers to non-managers wage ratios (in case the assumption that they lack inter-industry variation is relaxed), or various industry-specific labor laws and federal subsidy initiatives.

Fourth, motivated by insights from Acemoglu, Aghion, Lelarge, and Van Reenen (2007) and Garicano and Rossi-Hansberg (2012) the vector X includes the following controls (henceforth, firm controls): ${ }^{29}$ the age, R\&D intensity, assets, and output of a firm. Realizing that older firms might have a more established structure and culture, the first measure controls for potential differences in the flexibility of undertaking organizational reforms. Addressing potentially related U-shaped effects, we also include the square term of age. The second variable, measured as the share of $\mathrm{R} \& \mathrm{D}$ expenditure and royalty payments for technical knowhow in GVA, captures differences in technological orientation, which is essential for considering the organizational effects of technological flows. The third variable controls for firm size, given that larger firms may have greater management needs. The last variable controls for firms' output, following the analytical framework and Equation (3). Later we discuss separately further controls and potential channels.

We begin by closely following Equation (3), estimating a version of Equation (4) where the relevant independent variables are in their natural logarithm form. Specifically, these include the normalized trade-related measures. Since, however, some firms do not import or export, these were increased by one prior to conversion, to be able to exploit the sample to its fullest. For consistency we repeat this modification for all logarithmic conversions done throughout the analysis. ${ }^{30}$

Results appear in Table 3. Starting with imports, denoted by $T$ in Equation (4), Column (1) presents the benchmark setting. As can be seen, our coefficient of interest is positive and

\footnotetext{
${ }^{28}$ Until the 1980s large firms were required to obtain an operating license, and FDI was capped at $40 \%$ in most industries. Starting in 1985, and continuing in the 1990s, industries went through both a delicensing reform, where the abovementioned requirement was dropped, and a FDI-liberalization process (see e.g. Nataraj (2011)). Chamarbagwala and Sharma (2011) note that the delicensing process helped to upgrade firms' skill intensity, emphasizing further the relevance of controlling for this in our context.

${ }^{29}$ Nonetheless, we note that all results are robust to its exclusion.

${ }^{30}$ We note that all results hold, both qualitatively and quantitatively, without this manual addition in any of the logarithmic variables used in the estimations. We prefer it as the alternative would result in testing smaller samples and raising further sample-selection related concerns.
} 
significant. Imports and the relative demand for managers are positively related. In addition, the magnitude is economically meaningful: a 1\% increase in the GVA share of total imports increases the compensation share of managers by approximately $0.1 \%$.

An initial implication of these observations, together with the patterns outlined in Figure 2, is that this refutes the possibility that a simple administrative reclassification of workers is driving the increasing trend observed on our outcome variable in Figure 1. This applies assuming that such reclassification is not a specific feature of importing firms, and because the abovementioned delicensing process is controlled for.

Turning to exports, Column (2) replicates Column (1) with $T$ denoting exports. As can be seen, unlike imports this case yields statistically insignificant results with lower magnitudes. To better observe the distinction between the two, in Column (3) we again follow the same specification of Column (1) yet we include both imports and exports concurrently. The results clearly point at imports as being the triggering factor. Next, we examine which types of imports drive this.

\subsubsection{Disaggregating imports: The role of imported inputs}

Following the above, we dig deeper into the effects of imports and disaggregate them to various groups, to investigate their separate effects on the relative demand for managers. All estimations follow the benchmark specification of Column (1), with the respective import type in lieu of $T$, as specified.

The data enable us to disaggregate imports to four sub-groups: raw materials, capital goods, stores and spares, and finished goods. The aggregation of the first two represents the group of intermediate inputs, with the other two being non-inputs. In Column (4) we estimate Equation (4) for imports of inputs and non-inputs, together with exports. The positive and significant result on inputs, together with the near-zero and non-significant result on non-inputs and exports, indicate that it is specifically imported inputs that are associated with increases in the compensation share of managers. Following exercises, focusing on input tariffs, will reveal this association is highly persistent and robust.

Which inputs are dominant? To address that, we estimate in Column (5) a specification that includes the four sub-groups together, in addition to exports. The pattern observed is clear. The overall effect outlined previously is driven in its entirely by imports of capital goods, given its precisely estimated positive $\beta$, in contrast to those of the other types, including exports, which appear imprecise and with smaller magnitudes. As capital goods is the relatively technological-intensive sub-group of intermediate inputs, this is consistent with the initial hypothesis that intermediate inputs may increase the relative demand for managers via an increase in demand for managing 
the new incoming technology. Interestingly, these patterns are consistent with Bloom, Garicano, Sadun, and Van Reenen (2014) who find that ICT capital increases managers' span of control. ${ }^{31}$

\subsection{Main analysis: Changes in tariffs}

To this point our analysis revolved around trade measures, motivating a focus on imported inputs. Next, we turn the focus to trade liberalization directly. Motivated by the initial trade-related results, we examine changes in tariffs - a major liberalization tool- with an emphasis on those related to intermediate inputs. In addition, this enables addressing various econometric issues that may have plagued the initial analysis, the most notable one being the potential endogeneity of imports to the relative demand for managers. We address this concern, among others, in this subsection. To do so, we exploit a quasi-natural experiment: The 1990s trade reform in India. We describe it next.

\subsubsection{India's trade reform: A quasi-natural experiment}

Prior to 1990 India was one of the most trade-restrictive economies in Asia, having high tariff and non-tariff barriers. In 1991, India turned to the IMF, following a balance-of-payments crisis, for assistance. The latter conditioned such assistance on an implementation of a major adjustment program that was to include also liberalization steps that would abandon the restrictive trade policies. As a result, average tariffs fell by more than half between 1990 and 1996 (Topalova and Khandelwal (2011)). Non-tariff barriers made a similar drop between the late 1980s and the mid1990s (Goldberg, Khandelwal, Pavcnik, and Topalova (2010)). More specifically, starting at around 150 in 1990, the average tariff level dropped to approximately tenth of that by 2006 . These major tariff changes form the key policy measure we exploit.

This trade reform presents several advantages that make it appealing for the purposes of this study. First, the crisis that led to the adjustment program was triggered by external events, such as the sudden increases in oil prices, drop in remittances from Indian workers abroad, and major political occurrences (the murder of Rajiv Gandhi, for instance) that damaged foreign investment. This, in turn, in conjunction with the fact that reforms were passed quickly, led to sudden changes that were unanticipated by Indian firms, establishing the reform as being a quasi-natural experiment.

Second, the liberalization reform did not seem to have targeted industries within the manufacturing sector in a way that was related to pre-reform conditions. Indeed, Topalova and Khandelwal

\footnotetext{
${ }^{31}$ To the extent that higher demand for managers is associated with better management practices, these patterns are also consistent with those documented by Bloom, Manova, Sun, Van Reenen, and Yu (2016). They find that better managed firms in China and the US use more imported inputs, and specifically, more expensive and higher quality inputs.
} 
(2011) show that changes in industry-level tariffs during the years 1991-1997 were not correlated with pre-reform industry characteristics. In the empirical analysis we follow this finding by restricting the causal analysis to the same period; we discuss this further in the estimations. In addition, we verify in the Appendix that changes in the industry-level tariffs were not associated with past industry-level measures of managerial compensation. ${ }^{32}$ Importantly, this further establishes the plausibly exogenous nature of the reform and the shocks we study.

Third, there is much variation in the tariff changes across industries. While being reported in previous studies (e.g. Topalova and Khandelwal (2011)), this feature is also observed in our sample. The 4-digit industry-level average annual decreases in tariffs range from as low as $2 \%$ to as high as $25 \%$, with a mean of $6 \%$ and a standard deviation of approximately $2.5 \%$. Last, the usage of this quasi-natural experiment as a tool to identify the effects of trade liberalization on firm-level behavior has been done in several previous studies, ${ }^{33}$ thus establishing its familiarity and reliability. We exploit this feature next, as we outline our empirical strategy.

\subsubsection{Tariff data and empirical strategy}

We complement the firm-level data with tariff rates. Tariff data are derived from the TRAINSWITS tariff database, at the HS 6-digit level. We pass these output tariffs through India's inputoutput matrix for 1993-1994 to construct input tariffs, $\tau_{j, t}^{\text {input }}$, as follows: $\tau_{j, t}^{\text {input }}=\sum_{k} a_{k, j} \tau_{k, t}^{\text {output }}$, where $\tau_{k, t}^{\text {output }}$ is the tariff on industry $k$ at time $t$, and $a_{k, j}$ is the share of industry $k$ in the value of industry $j .{ }^{34}$ We concord both the input and output tariffs to the 4-digit 2004 NIC level using the Debroy and Santhanam (1993) concordance table. ${ }^{35}$ The tariffs are then matched with our firm-level data.

Hence, consistent with our analytical framework, which takes a within-industry perspective, and similar to Ahsan (2013) and Ahsan and Mitra (2014), we investigate industry-level tariffs.

\footnotetext{
${ }^{32}$ This is discussed in Appendix E, with the results presented in Appendix Tables 14 and 15.

${ }^{33}$ See e.g. Ahsan (2013), Goldberg, Khandelwal, Pavcnik, and Topalova (2010), and Topalova and Khandelwal (2011).

${ }^{34}$ In effect, we follow the methodology used in De Loecker, Goldberg, Khandelwal, and Pavcnik (2016). Fixing the input-output weights at 1993-1994 addresses related potential endogeneity concerns. Goldberg, Khandelwal, Pavcnik, and Topalova (2010) report that this input-output table likely reflects India's production technology across industries at the start of the reform period. Nonetheless, we show in a later sub-section that the main results are robust to setting the initial year of the sample to 1993.

${ }^{35}$ The concordance methodology employs the Debroy and Santhanam (1993) schedule to calculate (simple) average industry-level tariffs. This follows the methodology of previous studies that examined the effects of changes in (input and output) tariffs in Indian industries (e.g. De Loecker, Goldberg, Khandelwal, and Pavcnik (2016), Goldberg, Khandelwal, Pavcnik, and Topalova (2010), and Topalova and Khandelwal (2011)). As outlined in Topalova (2010), this methodology provides a relatively precise measure of industry-level tariffs in India. Similarly, this concordance procedure is undertaken in all cases that report using the Debroy and Santhanam (1993) schedule throughout the analysis.
} 
The empirical strategy builds upon the exogeneity feature discussed above to undertake the main analysis using OLS. Realizing tariff changes may have a lagging effect, and to better address further endogeneity concerns we consider liberalization shocks in the previous period (albeit experimenting with different lags later in the analysis). In effect, we follow the empirical strategy of previous studies that investigated the effects of trade liberalization using the same reform (e.g. Topalova and Khandelwal (2011)).

\subsubsection{Input tariffs: Causal Inference}

We estimate the tariff-based version of Equation (4), for firm $i$, in industry $j$, at time $t$ using the following reduced form equation:

$$
\frac{M \operatorname{comp}}{\text { Tcomp }}_{i, t}=\alpha+\beta \ln (\text { InpTar })_{j, t-1}+\gamma \mathbf{X}_{i, t-1}+\delta_{i}+\eta_{t}+(\text { Ind } * \text { Trend })_{j}+\epsilon_{i, t},
$$

where InpTar refers to input tariff. The remaining notation follows that described previously. The specification is similar to that of Equation (4) with the industry by year fixed effects excluded due to their absorption of the industry-level tariffs. Instead, we include industry-specific time trends. In addition, $\mathbf{X}$ enters the model in $t-1$, to further mitigate related endogeneity concerns. We follow Ahsan and Mitra (2014) and Topalova and Khandelwal (2011) and cluster the standard errors at the industry-level. ${ }^{36}$ Guided by the results of the preliminary analysis, which point at imported inputs as the triggering factor, our main focus is on input tariffs. We nonetheless consider the case of output tariffs, yet relegate their analysis to the Appendix.

Our focus is on the coefficient $\beta$. Results appear in Table 4. Column (1) presents the benchmark case. Consistent with the preliminary analysis, $\beta$ is precisely estimated and negative, indicating that input-trade liberalization increases the relative demand for managers. Interpreting the magnitude, a $10 \%$ reduction in input tariffs induces an increase of $1 \%$ in the compensation share of managers. Column (2), which estimates a dynamic version of Equation (5), provides a similar result. Considering the previously discussed finding of Topalova and Khandelwal (2011) on the exogeneity of tariff changes to industry characteristics during the 1990s, in Columns (3)-(4) we follow the estimations of Columns (1)-(2) under the restricted sample period of 1990-1997. The results are qualitatively similar to those obtained under the initial cases, yet are quantitatively stronger.

To observe the source of the change in the relative demand for managers more clearly, we disaggregate the ratio to its two main components, managers' and non-managers' compensation, and test the GVA share of each separately as the dependent variable. Results appear in Columns

\footnotetext{
${ }^{36}$ Nonetheless, we note that results are maintained, with high stability, when otherwise clustering the standard errors at the firm level.
} 
(5) and (6). The distinction, observed via the estimated $\beta \mathrm{s}$, is clear. Decreases in input tariffs increases managers' compensation, yet do not affect that of non-managers. This indicates that the relative demand for managers increases because of an increase in managers' compensation rather than due to a decrease or a relatively smaller increase in the compensation of non-managers. This, in turn, suggests that the main effect is not driven by outsourcing of non-managerial tasks or other specific schemes that may bring major layoffs on the non-managers' side. ${ }^{37}$

Last, although the primary focus is on input tariffs we present an equivalent analysis using output tariffs in the Appendix Table 16. Notably, the effect of output tariffs on the relative demand for managers is similar to that of input tariffs, when examined independently. However, when both input and output tariffs are included concurrently, as in Columns (3) and (4), the coefficient on output tariffs drops to approximately 0 and loses its preciseness whereas that on input tariffs remains stable in magnitude and significance as in the benchmark cases. This suggests that the effect observed on output tariffs works through the input side, contributing to the latter's relative dominance, and strengthening the initial observation on the triggering effect of imported intermediate inputs.

Importantly, this also provides some insights on the potential underlying mechanism. While a decrease in output tariffs may stiffen product market (import) competition (Amiti and Konings (2007)), a decrease in input tariffs increases the technological complexity of the production process. The latter is a feature of the higher quality and variety of imported inputs (Acemoglu and Zilibotti (2001), Eaton and Kortum (1996), and Goldberg, Khandelwal, Pavcnik, and Topalova (2010)). The dominating effect of input tariffs suggests that the observed increase in the relative demand of managers is triggered by changes in the production technologies rather than by a stronger competition in the final goods market.

To observe more clearly that import competition is weakly associated with changes in the relative demand for managers, we test an additional, standard import competition measure: the industrylevel share of Chinese-sourced imports in total (Indian) imports. ${ }^{38}$ Import data are derived from the UN-COMTRADE database at the HS 6-digit level and converted to the 4-digit 2004 NIC level using the Debroy and Santhanam (1993) concordance table. Results with this measure are presented in Columns (5)-(8) of Appendix Table 16, which follow the same specifications as Columns (1)-(4) only with this measure in lieu of output tariffs. The estimated coefficients on input tariffs in all cases is similar to those estimated in Columns (1)-(4), further indicating that the effect we observe

\footnotetext{
${ }^{37}$ These include, for instance, potential effects of input-trade liberalization on firms' exit rates, as well as mergers and acquisitions, which if were applicable would have affected the non-managers side.

${ }^{38}$ See e.g. Acemoglu, Autor, Dorn, Hanson, and Price (2016), and Autor, Dorn, and Hanson (2013) who adopt a similar proxy for the U.S. case.
} 
works through changes in the production side.

\subsubsection{Components of the relative demand for managers}

The benchmark analysis illustrated that input tariffs increase the relative demand for managers via increases in managerial compensation. In this sub-section we examine the components of the latter, to better understand the sources of the change. We begin with disaggregating managers' compensation to its smaller ingredients, exploiting the full extent of available data on this. All specifications follow the benchmark one as in Column (1) of Table 4, with the dependent variable changing between cases. Results appear in Table 5.

Hence, we disaggregate managers' compensation to its two main components: wages and bonuses. ${ }^{39}$ The former is the pre-determined salary received by the employees, whereas the latter is incentive-based, often being linked to performance. Each is examined in Columns (1) and (2), respectively, using relative terms, similar to our benchmark dependent variable in Equation (5). This means using Managers $s_{j} /\left(\right.$ Managers $_{j}+$ Non - Manager $\left._{j}\right)$, where $j \in$ (wage,bonus), as the dependent variable in each of the cases. Notably, $\beta$ in both cases is negative and statistically significant. This indicates that input-trade liberalization increases both relative wages and relative bonuses of managers, ${ }^{40}$ which when combined make a relative increase in managers' compensation.

Following an examination of the compensation components, we next look into the number of managers. If input-trade liberalization changes the number of managers, the compensation share can change even without changes in wages, making this distinct, yet complementary, to the previous exercise. Hence, we exploit a feature in the firm-level data that lists the executives (by name) for more than half of our firm-year observations to count their number. ${ }^{41}$ We make two initial observations with this measure. First, the average number of executives in Indian firms has been steadily increasing over our sample period; this is plotted in Figure 4, where we see that it is close to 0 in 1990, and is increasing continuously up to almost 0.6 in 2006 . Second, when dividing the sample to importing and non-importing firms, we once again note that the average increase observed over the entire sample is driven almost entirely by the importing firms; this is plotted in Figure 5. To test this, in Column (3) of Table $\mathbf{5}$ we estimate our benchmark specification using the number of executives as the outcome variable. The precisely estimated negative $\beta$ confirms

\footnotetext{
${ }^{39}$ Note that this disaggregation is not available for all firm-years, decreasing the sample size by almost one half.

${ }^{40}$ Interestingly, these results are consistent with those reported by Cunat and Guadalupe (2009), who found that import penetration increases the sensitivity of pay-to-performance of US executives, hence indicating that these patterns are not confined to developed economies.

${ }^{41}$ The data set also lists the directors (by name) yet only for approximately $10 \%$ of the sampled firms (note that this is separate from reporting compensation data at this level, which has better coverage). We do note that the patterns presented hold as well when middle management is included, yet due to the significant drop in sample size we focus strictly on the case of executives.
} 
that input-trade liberalization increases the number of executives.

Realizing that a decrease in input tariffs increases both the compensation and number of managers, we next examine the change in the average (per-executive) compensation components. In Columns (4)-(5) of Table $\mathbf{5}$ we follow the benchmark specification using the average executive wage and bonus as the outcome variables, respectively. The estimated $\beta$ s indicate that both of the per-executive compensation measures increase following a drop in input tariffs. These estimates, together with the previous results, suggest that the observed increase in managerial compensation is an outcome of a joint increase in their number as well as in their average wages and bonuses.

\subsubsection{Firm characteristics}

In this sub-section we look into various firm characteristics, in an attempt to identify the type of firms that drive the main result. To do so, we estimate the following variation of Equation (5):

$$
\begin{aligned}
\frac{M \operatorname{comp}}{T \operatorname{comp}}_{i, t}=\alpha+\beta \ln (\operatorname{InpTar} * C)_{i, t-1}+\theta \ln (\operatorname{InpTar} * D)_{i, t-1} & \\
& +\gamma \mathbf{X}_{i, t-1}+\delta_{i}+\eta_{t}+(\text { Ind } * \text { Trend })_{j}+\epsilon_{i, t},
\end{aligned}
$$

where $C$ is a dummy variable that captures one of four characteristics we outline below, and $D$ is a dummy variable that captures the remaining firm-year observations. Note that since the average effect (InpTar) is excluded, $C$ and $D$ can be estimated concurrently. In this case, therefore, $\beta$ and $\theta$ provide the relative portion of each in the total, average effect. The remaining notation and estimation details follow those of Equation (5). Results in this sub-section appear in Table 6.

We start with firm size. Although we control for it, we seek to realize whether the main effect differentiates across the firms' size distribution. Considering GVA as a proxy for size, $C$ $(D)$ captures above (below) median firm-year observations of GVA. Results appear in Column (1), indicating that the main effect is apparent in both groups, and in equal magnitude. To better illustrate this, in the Appendix Figure A1 we plot a version of Figure $\mathbf{2}$ for four GVA-based size-quartiles. The post-1995 hike in the compensation share of managers in the importing firms is equivalently apparent in all four cases.

Second, we look into export orientation. The initial analysis indicated that the effect is restricted to importing firms; however, following related insights of Caliendo and Rossi-Hansberg (2012) and Mion and Opromolla (2014) on exporting firms, we examine whether the export decision of input importing firms may affect the patterns observed. Hence, in this case $C(D)$ represents the firmyear observations in which exports are positive (zero). The results, in Column (2), show that the main effect applies in equal magnitudes to both groups. Firms that import inputs increase their 
managerial compensation irrespective of their export orientation. ${ }^{42}$

Third, we examine firms' end use. We follow Nouroz (2001) and use the input-output classifications to categorize firms by the end use of their products. The division is thus made into two groups: intermediate and final goods. The former (latter) includes firms for which the end use of their products are classified as intermediates, basic, or capital (consumer durables and nondurables), and is captured via $C(D)$. Results appear in Column (3). We see that the main result is a feature of firms that belong to the intermediate goods group.

Last, we examine firm ownership. The data divides firm ownership to two main categories, domestic and foreign owned. In this case $C(D)$ captures the former (latter). Results appear in Column (4). Our coefficients of interest indicate that the main result is entirely driven by domestically owned firms. This result implies that the change in managerial demand is not a feature of foreign organizational culture inflows from abroad. Put together with the previous results, the subset of firms that drive the main result are those domestically owned firms that import inputs to produce intermediate goods.

\subsubsection{Family firms}

This sub-section examines the role of family firms. The selection pool and preferences of family managers differ from those of professional ones (Bandiera, Lemos, Prat, and Sadun (2017)), which may yield different reactions to changes in trade policies. Realizing that family firms take a central role in the Indian economy (Bloom, Eifert, Mahajan, McKenzie, and Roberts (2013)), examining their reaction may be pivotal to understanding the observed patterns of managerial compensation. To do so, we estimate the following version of Equation (5):

$$
\begin{aligned}
\frac{M c o m p}{T \operatorname{comp}}_{i, t}=\alpha+\beta \ln (\operatorname{InpTar})_{j, t-1}+\phi F_{i}+\theta \ln (\operatorname{InpTar} * F)_{i, t-1} & \\
& +\gamma \mathbf{X}_{i, t-1}+\delta_{i}+\eta_{t}+(\text { Ind } * \text { Trend })_{j}+\epsilon_{i, t} .
\end{aligned}
$$

The difference from Equation (5) lies in $F$, an indicator for family firms, and its interaction with the input tariffs. We identify family firms by following the approach of the Securities and Exchange Board of India (SEBI). SEBI defines a family firm to be one that is at least partly owned by Hindu undivided families. ${ }^{43}$ Based on this, we construct four versions of $F$ : i) a binary indicator

\footnotetext{
${ }^{42}$ The analysis in Caliendo and Rossi-Hansberg (2012) indicates that trade liberalization may increase management layers in exporting firms. They consider a demand shock (bilateral trade liberalization) that may affect exporting firms more strongly. Conversely, we consider a demand shock (input-trade liberalization) that affects input-dependent firms, rather than those that export.

${ }^{43}$ According to Hindu law, a Hindu undivided family is one that consists of all persons lineally descendent from a common ancestor.
} 
that takes the value of 1 for firms with positive equity share of Hindu undivided families; ii) the equity share of Hindu undivided families; iii) a binary indicator that takes the value of 1 for firms in which Hindu undivided families have an equity share higher than 30\%; iv) a binary indicator that is similar to the one described in (iii), only with a cut-off of $50 \%$. In effect, the first indicator follows SEBI's definition of a family firm. Interestingly, it indicates that about $67 \%$ of the firms in our sample are considered family firms, ${ }^{44}$ supporting the prominence of the Indian family-oriented firm culture. ${ }^{45}$ The second measure indicates that the ownership share of Hindu undivided families has a mean of $8 \%$, and ranges from $0 \%$ to about $94 \%$, as outlined in Table 2 . The third and fourth measures consider stricter definitions, under which a firm is considered family-owned if the equity share of Hindu undivided families is substantial.

Importantly, firms started disclosing ownership information to SEBI in 2007. In an attempt to mitigate potential measurement errors, we compute the average equity share of Hindu undivided families over the period 2007-2009, and use that to create a cross-sectional division of firms, under the assumption that firms that reported being family owned in 2007-2009 were also such during our sample period (1990-2006). This assumption is based primarily on the definition of Hindu undivided families, which takes a cross-generational perspective, especially in cases of substantial equity share. This is supported by the findings of Patnaik (2014) that indicate that family ownership patterns in publicly-listed Indian firms have little variation during parts of our sample period.

Under these conditions $F$ variates solely across firms. Hence, albeit being included in Equation $(7)$, it is in fact absorbed by $\delta$; our focus is, therefore, on the heterogeneous effect, $\theta$. Results appear in Table 7. In each of the Columns (1)-(4) $F$ represents each of its four versions, respectively. In all cases $\theta$ is negative, statistically significant, and has a significantly larger magnitude than that of the baseline average effect. Interestingly, the magnitude of $\theta$ increases with the equity share of Hindu undivided families. These patterns suggest that input-trade liberalization affects the relative demand for managers primarily in family-owned firms. Notably, this is consistent with findings of related studies on labor market adjustments to trade shocks, in both high and low income countries (Chen and Steinwender (2017), McCaig and Pavcnik (2014), McCaig and Pavcnik (2015)).

To better observe that this is specific to family firms, in the Appendix we consider the role of two additional standard (time-varying) measures of governance structure: the number of independent

\footnotetext{
${ }^{44}$ Nonetheless, this indicator does not cover all the firms with family ownership. For instance, some firms do not report ownership of undivided families, yet they may still be family-owned firms via pyramid structures of ownership. Patnaik (2014) considers these limitations and concludes that SEBI's definition captures the vast majority of family firms in PROWESS.

${ }^{45}$ Notably, Bloom, Eifert, Mahajan, McKenzie, and Roberts (2013) have 100\% family ownership in their sample of Indian textile plants, and Bloom and Van Reenen (2010) indicate that $75 \%$ of firms in their sample of Indian manufacturing plants are family owned. Nonetheless, we focus on publicly listed firms in which there is a higher share of non-family firms compared to the set of private firms.
} 
directors, and the size of the board of directors. ${ }^{46}$ As discussed in the Appendix, this analysis indicates that input-trade liberalization does not lead to changes in these governance measures, and does not yield heterogeneous effects on managers' compensation across different levels of these measures.

\subsubsection{Labor market regulations and firm location}

Labor market institutions may shape managerial incentives. For instance, Bloom and Van Reenen (2010) find that heavily regulated labor markets are associated with poor management practices. This may be important in the Indian context, in which labor markets are considered relatively rigid (Topalova (2010)). In this sub-section we examine the impact of labor market regulations on the association between input-trade liberalization and the demand for managers. We do so by exploiting cross-state variation in labor institutions, interacted with firms' state-locations.

A key difference in labor market institutions across Indian states is based on state-amendments made to the federal Industrial Disputes Act. Besley and Burgess (2004) examine all the 113 amendments made by state governments between 1958 and 1992 and code them as pro-employee, pro-employer, or neutral. We employ an update of this index, constructed by Aghion, Burgess, Redding, and Zilibotti (2008). ${ }^{47}$ This indicator records a value between -2 and 4 for each state, with the former (latter) representing inflexible, pro-employer (flexible, pro-employee) labor market regulations. In light of potential endogeneity concerns, we examine cross-state differences in 1990. Notably, there were only marginal changes in state labor institutions between the start and end of our sample period, as noted in Chaurey (2015).

We then interact this index with firms' state-locations, coded via their reported postcodes. CMIE reports firms' postcodes based on their current location; ${ }^{48}$ consequently, we consider firms' state-locations in 2011. The applicability of this cross-sectional division is based on the observation that cross-state factor mobility in India is considerably low, as noted by Topalova (2010) and Siddharth (2008). Importantly, Topalova (2010) shows that labor remained immobile following the trade reform we investigate.

\footnotetext{
${ }^{46}$ This is presented in Appendix F, with the results presented in Appendix Table 17.

${ }^{47}$ This index is not available for the following states: Delhi, Himachal Pradesh, Manipur, Meghalaya, and Nagaland. This restricts the sample size.

${ }^{48}$ In effect, firms report their postcodes annually, yet in case of a change in the postcode CMIE over-writes the new location, without keeping track of previous ones.
} 
Hence, we estimate variates of the following model:

$$
\begin{aligned}
\frac{M \operatorname{comp}}{\text { Tcomp }}_{i, t}=\alpha+\beta \ln (\text { InpTar })_{j, t-1}+\phi \text { Labor }_{i}+ & \theta \ln (\text { InpTar } * \text { Labor })_{i, t-1} \\
& +\gamma \mathbf{X}_{i, t-1}+\delta_{i}+\eta_{t}+(\text { Ind } * \text { Trend })_{j}+\epsilon_{i, t}
\end{aligned}
$$

where Labor represents the labor market regulations index described above, interacted with the firms' state-location. Notice that its average effect is absorbed by $\delta$, given that it has no time variation. Results appear in Table 8. Column (1) follows the specified model; Column (2) estimates a dynamic version of it. In both cases, $\beta$ remains negative and significant, with a stable magnitude. The main result is, thus, robust to this inclusion. Interestingly, both cases yield a positive and significant $\theta$. Input-trade liberalization affects the compensation share of managers more strongly in firms that are located in states with more flexible, pro-employee labor market regulations.

To test the robustness of this, in the Appendix we undertake a similar analysis using a different cross-sectional index, derived from Gupta, Hasan, and Kumar (2009). ${ }^{49}$ As outlined in the Appendix, this analysis yields similar patterns. In addition, in Columns (3) and (4) of Table 8 we take a more general approach and estimate Equation (5), and its dynamic version, with state by year fixed effects. The latter control for time-varying cross-state differences in labor market regulations, as well as other institutional differences. Both cases indicate that the main result remains to hold under this addition.

\subsubsection{Short vs. long term effects}

Our analysis focuses primarily on 1-year lag, short-run effects of input-trade liberalization on managerial compensation. This suggests that the observed impact may be an outcome of changes that occur within relatively short timeframes, such as for instance updates in management practices. Nonetheless, input tariffs may also affect the compensation of managers via changes that are expected to occur over longer timeframes, such as general equilibrium adjustments of prices, outputs, or even the supply of managers.

To examine the role of time dynamics we estimate the following model:

$$
\frac{M \operatorname{comp}}{\text { Tcomp }}_{i, t}=\alpha+\beta \ln (\text { InpTar })_{j, t-n}+\gamma \mathbf{X}_{i, t-1}+\delta_{i}+\eta_{t}+(\text { Ind } * \text { Trend })_{j}+\epsilon_{i, t},
$$

where $n \in[0,3]$. This specification is equivalent to Equation (5) with the difference of considering the impact of input tariffs at different periods, ranging from its contemporaneous level $(n=0)$, to its measure in $t-3(n=3)$. Our focus is on $\beta$, yet given that under these specifications the sample

\footnotetext{
${ }^{49}$ This is discussed in Appendix G, with the results presented in Appendix Table 18.
} 
is more restricted, we put greater emphasis on interpreting magnitudes, rather than preciseness.

Results appear in Table 9. Columns (1)-(3) test the cases of 0, 2, and 3-year lag in input tariffs, respectively. ${ }^{50}$ In all cases the sign of $\beta$ is similar to the one estimated in the 1-year lag specification. However, the estimated magnitudes suggest that any potential contemporaneous and 2 -year lag effects are relatively weaker. Conversely, the effects of changes in input tariffs in $t-3$ appear to be largely equivalent to those observed in the baseline, 1-year lag case.

To put this to further test we estimate variates of the following, more demanding specification:

$$
\begin{aligned}
\frac{M c o m p}{T c o m p}_{i, t}=\alpha+\beta \ln (\text { InpTar })_{j, t}+\zeta \ln (\text { InpTar })_{j, t-1}+\vartheta \ln (\text { InpTar })_{j, t-2}+ \\
\nu \ln (\text { InpTar })_{j, t-3}+\gamma \mathbf{X}_{i, t-1}+\delta_{i}+\eta_{t}+(\text { Ind } * \text { Trend })_{j}+\epsilon_{i, t}
\end{aligned}
$$

in which the different lags (0 up to 3 ) of input tariffs are concurrently included. Column (4) follows this specification; Column (5) estimates its dynamic version. In both cases we see that input tariffs affect the share of managerial compensation when it is in either its 1-year or 3-year lag versions. This suggests that both short and long term changes are applicable to some extent, yet the former is more dominant given that the 1-year lag effect appears relatively stronger and more robust.

\subsubsection{Additional controls}

Having identified the main effect, we next consider further controls and potential intermediate channels. Results appear in Table 10. ${ }^{51}$ All specifications in this sub-section follow variations of the following model:

$$
\begin{aligned}
\frac{M \operatorname{comp}}{\operatorname{Tcomp}}_{i, t}=\alpha+\beta \ln (\operatorname{InpTar})_{j, t-1}+\phi Z_{j, t-1} & +\theta \ln (\operatorname{InpTar} * Z)_{j, t-1} \\
& +\gamma \mathbf{X}_{i, t-1}+\delta_{i}+\eta_{t}+(\text { Ind } * \text { Trend })_{j}+\epsilon_{i, t} .
\end{aligned}
$$

Notation is similar to that described in Equation (5), with the addition of $Z$ which represents one of five additional controls: skill, capital intensity, productivity, export tariffs, and management technology. $Z$ enters together with its interaction with $\operatorname{InpTar}$, at $t-1 .^{52} \mathrm{In}$ each case we focus on two points. First, we consider the role of the additional control as an intermediate channel, by examining its direct effect via $\phi$ as well as its indirect one via changes in the magnitude, and possibly precision, of $\beta$. Second, we undertake a heterogeneity analysis, testing whether the main effect is

\footnotetext{
${ }^{50}$ The case of 1-year lag is already considered under the baseline estimation, and hence not presented in this analysis.

${ }^{51}$ Note that the number of observations may change between cases, due to data availability of the various additional controls.

${ }^{52}$ Notice that it can take the subscript $j$ or $i$, depending on whether $Z$ is at the firm or industry level.
} 
systematically different across initial levels of the measure tested, by examining the properties of the parameter $\theta$.

We start with the potential connection between managers and skilled labor. ${ }^{53}$ We measure the latter through the 3-digit industry level ratio of non-production workers to all workers, being the standard skill intensity measure used in the literature. ${ }^{54}$ This measure is obtained from Ghosh (2014) (1990-2000), ${ }^{55}$ and the Indian Annual Survey of Industries (2001-2006). ${ }^{56}$ Previous studies indicate that globalization increases the demand for skill in developing economies (Goldberg and Pavcnik (2007)). This, in turn, may affect the demand for managers. To test this, in Column (1) we add the skill intensity variable. The coefficient $\beta$ remains stable and precise, suggesting that skill in the broader sense, measured via the demand for non-production workers, is not a prominent intermediate channel. In addition, the interaction of skill with InpTar indicates that there is no apparent differential effect across industries' benchmark skill intensity levels. ${ }^{57}$

Second, we test the effect of capital intensity. Our key variable, intermediate inputs, is a flow measure of incoming equipment. The stock value of capital, which includes non-equipment stock as well, may also affect the demand for managers. For instance, capital intensive production processes may involve automation and hence less problem solving and less demand for managers, compared to labor intensive production technologies. To test the role of capital intensity in our main effect, in Column (2) we add firms' GVA share of capital employed. Its direct effect is weakly positive and statistically imprecise, providing no support that the stock of capital is correlated with the compensation share of managers. Importantly, $\beta$ does not change relative to the benchmark case, indicating that the effect of the incoming flow of equipment on the relative demand for managers holds regardless of whether the firm is relatively capital intensive. Notably, the interaction of this measure with InpTar does not point at systematic differential effects across capital intensity levels.

\footnotetext{
${ }^{53}$ At first glance it may be susceptible that skill and managers might be correlated through the standard definition of skill in the literature which considers non-production workers or otherwise those in white collar occupations. Note however that this definition, while covering also managers, includes various additional occupations that do not necessarily hold managerial positions. For instance, in the cases of Berman, Bound, and Griliches (1994) and Zhu and Trefler (2005), skilled workers are defined to hold the following positions within the manufacturing sector: manager, professional, technician, and clerical worker; indeed managers represent a subset of that, though the other professions can fall under the non-managers classification.

${ }^{54}$ Proxying skill intensity by 'non-production' is non-trivial, though this is common practice by necessity, given data limitations. Indeed, this measure is adopted by various studies on trade liberalization and skill in developing countries (e.g. Raveh and Reshef (2016), Zhu and Trefler (2005)). In addition, Berman, Bound, and Griliches (1994) show that the production/non-production worker classification is a good proxy for skilled and unskilled workers.

${ }^{55}$ We thank Sangeeta Ghosh for sharing this data.

${ }^{56}$ Notably, our proxies for the relative demand for managers and skill intensity do not correlate strongly at the industry level $(\rho=-0.13)$; an outcome of examining one occupation in a larger set of non-production ones.

${ }^{57}$ Given the potential importance of this measure in our analysis, in the Appendix we further verify that similar results are yielded when this measure, together with its interactions with the treatment, are added to the initial, trade-based analysis presented in Section 3.2. This is discussed in Appendix H, with the results presented in Appendix Table 19
} 
Third, we test the effect of productivity. Previous research shows that trade liberalization increases firm productivity (e.g. Topalova and Khandelwal (2011)). Higher productivity may increase the demand for managers due, for instance, to its potential effects on organizational design (Garicano (2000)). ${ }^{58}$ To test its intermediate effect, we add in Column (3) a measure of productivity. We follow Ahsan (2013) and Topalova and Khandelwal (2011), and adopt the Levinsohn and Petrin (2003) methodology to construct firm-level TFP. The latter controls for the potential simultaneity in the production function by using firms' raw material inputs as a proxy for the unobservable productivity shocks. ${ }^{59}$ The estimated $\phi$ indicates that productivity is not associated with the relative demand for managers. However, $\beta$ holds its magnitude and significance, suggesting that productivity is not a key intermediate channel. The estimated $\theta$ does not point at systematic differential patterns across productivity levels.

Fourth, we examine the role of export tariffs. During our sample period there were various multilateral trade liberalization episodes, such as for instance the 1995 Uruguay round, that affected the access of Indian firms to foreign markets. This, in turn, may have altered the demand for managers, irrespective of the domestic trade reforms. To test this, we control for export tariffs. This measure was constructed using HS6-level bilateral tariff data from the TRAINS-WITS database, for our sample period. In particular, we considered the cases that India is listed as an exporter. Using these, the tariffs of each industry were averaged over all trade partners, with the weight for each partner being its share in the Indian exports of that industry in 1990, calculated using data from the UN-COMTRADE database. Formally, we compute export tariffs, $\tau_{j, t}^{\exp \text { ort }}$, as follows: $\tau_{j, t}^{\exp \text { ort }}=\sum_{m} a_{m, j} \tau_{m, j, t}$, where $\tau_{m, j, t}$ is the tariff on industry $j$ at time $t$ for importing country $m$, and $a_{m, j}$ is the share of Indian exports (out of its total exports in industry $j$ ) to importer $m$ in 1990. We then mapped the export tariffs to the 4-digit NIC 2004 level using the Debroy and Santhanam (1993) concordance table. This measure is added in Column (4). The estimates indicate that the main result holds. This is in line with the observation that the main patterns are applicable in both exporting and non-exporting firms. Interestingly, however, the coefficient on the additional interaction term is negative and significant, implying that reductions in export tariffs intensify the main effect in input-liberalized industries.

Fifth, an additional potential determinant relates to management technology. In a recent study

\footnotetext{
${ }^{58}$ This may be especially prominent in the Indian economy. Hsieh and Klenow (2009) estimate that the 90th to the 10th percentiles of firms' TFP in India is 5.0, whereas Bloom, Eifert, Mahajan, McKenzie, and Roberts (2013) find that more productive Indian firms are also better managed.

${ }^{59}$ For firm $i$, in industry $j$, at time $t$, if $\omega_{i, j, t}$ is an unobservable productivity shock that might be correlated with the firm's choice of variable inputs, and demand function for intermediate inputs is monotonic in the firm's productivity, then Levinsohn and Petrin (2003) show that raw materials expenditure can act as a proxy for the unobservable shocks, which in turn enables to estimate the corresponding production function and TFP levels. See Levinsohn and Petrin (2003) for further details.
} 
Chen (2017) connects between trade liberalization and management technology. If better management technology requires a higher volume and quality of managers, it may represent a viable channel. To test this, we follow Chen (2017) and proxy management technology through the cross country-industry management survey done by Bloom and Van Reenen (2010). Surveying a large number of firms in various manufacturing industries in India (among other countries) throughout 2004, Bloom and Van Reenen (2010) construct a measure for management quality in different sectors. ${ }^{60}$ This index is a number between 1 and 5, with 5 representing the best quality. Given this measure is available for only one year, its average effect is absorbed by $\eta$; hence, we focus on its interaction with InpTar. The estimates in Column (5) indicate that input-trade liberalization does not have a systematically different effect on the relative demand for managers across industries' level of management technology.

Last, in Column (6) we include all the additional controls and their interactions with the input tariffs. This is a relatively demanding specification, in terms of potential multicollinearity. However, our primary coefficient of interest, $\beta$, remains negative and significant, similar to the benchmark estimates.

\subsubsection{Robustness tests}

As a final step, we conduct a few robustness tests to examine the persistency and stability of our main result. Results in this section are reported in Table 11. First, in Columns (1)-(4) we test our benchmark estimation under various specifications: using an industry-level and log versions of our dependent variable, as well as estimating a first-difference and Arellano-Bond (Arellano and Bond (1991)) versions of Equation (5), respectively. Although the magnitude slightly fluctuates, the main result remains to hold in sign and significance in all cases.

Second, we estimate a specification that adds the average wage of executive managers in the previous period to the baseline specification. Under the assumption that managers' wages factorin the (expected) quality of managers, based on their past experience and personal traits, this additional measure controls for managers' quality at the time of the shock. The estimates in Column (5) indicate that the main result is robust to this addition.

Third, we estimate the baseline specification while restricting the sample to post-1992 years. This restriction addresses potential endogeneity concerns related to the usage of India's inputoutput matrix in 1993-1994 by setting the initial year of the sample to 1993. The outcome in Column (6) indicates that the main result remains to hold under this restriction.

\footnotetext{
${ }^{60}$ The index is available at the 3-digit SIC level. We map this to 2-digit HS level via WITS correspondence tables, and thereafter to 2-digit NIC 2004 via the Debroy and Santhanam (1993) concordance table.
} 
Fourth, we test a different trade liberalization measure - imports normalized by domestic sales, being the import penetration measure used in Bloom, Sadun, and Van Reenen (2010). We use it in lieu of $\frac{T}{G V A}$ in specification (4). The result appears in Column (7), providing further support for the robustness of our key observation through the precision and sign of the coefficient of interest.

Last, we follow Goldberg, Khandelwal, Pavcnik, and Topalova (2010) and consider a firm-level input tariff measure. We do so by interacting the industry-level input tariffs with firms' GVA share of capital employed; formally, FirmTar ${ }_{i, t}=\operatorname{InpTar}_{j, t} * \frac{\operatorname{cap}}{G V A}{ }_{i, t}$. The intensity of capital employed is a direct measure of input intensity. The interaction, therefore, provides firm-level variation in the extent to which input tariffs may affect the firm. To that end, we examine this measure in the precedent period, FirmTar ${ }_{i, t-1}$, and add it to Equation (5) in lieu of $\operatorname{InpTar}_{j, t-1}$. Given the firm-level perspective we in addition exclude $\eta_{t}$ and $I n d * \operatorname{Trend}_{j}$, and instead include $\nu_{j} * \eta_{t}$. The outcome appears in Column (8), indicating that the main result remains to hold.

\subsection{Discussion of results}

Let us summarize the main results of our empirical analysis, and provide some further interpretations. The key findings were that imported inputs, and equivalently decreases in input tariffs, increase the compensation and number of managers, in relative and absolute terms, and across its components. This result was shown to be persistent, economically meaningful, robust to a myriad of tests and potential channels, and relatively more dominant in the short term. Digging deeper, the analysis pointed at the domestic, family-run firms that operate in relatively flexible labor markets, and use the imported inputs to produce intermediate goods, as those that drive the patterns observed. In addition, it revealed that neither firms' size nor export decision alter this. Last, it suggested that the role of import competition in this is relatively weak, and hence emphasized the potential importance of technology-driven changes in the production side.

Two key questions remain open. First, how do these findings may be important for understanding some of the key questions related to the impact of trade policies? Second, what are the potential underlying mechanisms that drive these results? In an attempt to address these questions, we draw on previous related empirical and theoretical research, and consider a possible conceptual framework that brings the above findings together.

Starting with the first question, the findings of this study may shed light on central issues related to the firm-level impacts of trade policies; specifically, those related to their effect on firm productivity, and growth. This is suggested by a growing body of empirical literature that

links management practices and quality, to firm productivity, performance, and growth. Some of the studies that provide evidence for this include Bloom, Brynjolfsson, Foster, Jarmin, Saporta- 
Eksten, and Van Reenen (2013), Bloom, Lemos, Sadun, Scur, and Van Reenen (2014), Bloom and Van Reenen (2007), Bloom and Van Reenen (2010), Caliendo, Monte, and Rossi-Hansberg (2015), Garicano and Rossi-Hansberg (2004), and Garicano and Rossi-Hansberg (2006). For instance, Bloom, Lemos, Sadun, Scur, and Van Reenen (2014) estimate that approximately a quarter of the cross-country and within-country TFP gaps can be accounted for by differences in management practices. Bloom, Eifert, Mahajan, McKenzie, and Roberts (2013) suggest that this may be even more prominent in the Indian context. ${ }^{61}$ While empirical analysis of these issues is beyond the scope of the current effort, the patterns we report point at a relatively understudied link between trade liberalization, and firm productivity and growth.

Moving to the second question, there is a line of empirical research that is quite revealing of the economic effects of the trade reform we investigate. Based on it, we identify three key outcomes of input-trade liberalization: first, it increases productivity (Ahsan (2013), Bas and Berthou (2017), and Topalova and Khandelwal (2011)); second, it increases product variety (Goldberg, Khandelwal, Pavcnik, and Topalova (2010)); third, it decreases marginal costs and increases markups (De Loecker, Goldberg, Khandelwal, and Pavcnik (2016)). Notably, all of the three outcomes suggest that input-liberalized firms undergo a demand shock. Caliendo and Rossi-Hansberg (2012) offer a theory in which firms that experience such a shock increase the number of management layers, based on the notion of knowledge hierarchies (Garicano (2000)), whereby firms economize on the problem solving process. This is consistent with the observed increase in product variety, pointing more directly at firm expansion. Both options suggest that the new knowledge arriving via decreased input tariffs yields an organizational expansion, and a demand for problem solving, that in turn increases the demand for managers, manifested via increases in their wages, bonuses, and number. The potential endogeneity of the previous outcomes to changes in managerial incentives may intensify this. Our results in addition suggest that this process may be stronger in family-run firms, where professional management is initially scarce.

Last, the potential role of capital-skill complementarity in this deserves further comment. ${ }^{62}$ Our findings indicate that capital imports increase the share of managerial compensation. The analyses in Section 3.3.9 and Appendix H suggest that these patterns are not driven by complementarities between capital and skill, as the main (and initial, trade-based) results are robust to holding the industry skill intensity level constant. To the extent that non-managers are relatively low-skilled, this is further strengthened by the observation in Section 3.3.3 that non-managerial compensation

\footnotetext{
${ }^{61}$ Through a field experiment involving Indian textile firms they find that better management practices can increase productivity by $17 \%$ in the first year, and lead to firm expansions within three years.

${ }^{62}$ The notion that capital may substitute low-skilled labor, often referred to as the capital-skill complementarity hypothesis, has been studied extensively in the literature (see e.g. Griliches (1969), and Krusell, Ohanian, Rios-Rull, and Violante (2000)).
} 
is relatively non-responsive to changes in input tariffs.

Nonetheless, we note the following. First, managers represent only a sub-set of the more general group of skilled labor. ${ }^{63}$ Hence, the non-managers group may include both high and low skilled labor (which are indistinguishable in our data). Under these circumstances, it may be that the observed patterns are driven to some extent by capital-skill complementarity, and non-managerial compensation appears non-responsive to imported capital because of the conflicting effects of imported capital on the high and low skilled labor within that group. Second, as noted the skill intensity measure employed in the analysis, namely the share of non-production workers, does not provide a clear mapping to the group of skilled labor, and is in addition available only at the 3-digit NIC 2004 level. This limits the extent to which the analysis can identify complementarities between inputs and skill and assess their importance in driving the results.

\section{Conclusion}

Understanding the effects of globalization on the labor market is of first-order importance. One aspect of this relates to intermediate inputs. Previous research indicate that input-trade liberalization brings new inputs and technologies. Studying their profound impact on productivity and output, the literature overlooked their potential effect on the demand for managing the new incoming knowledge. This may be prominent in light of the recently emerging literature on the link between trade liberalization and firm organization and its effects on productivity, especially in developing economies for which evidence on the trade-organization nexus are scarce. Hence, examining the association between imported inputs and managerial incentives may shed light on central issues such as the firm-level effects of trade policies. This paper made a first empirical attempt to fill this gap.

Adopting the case of India, we asked: can input-trade liberalization increase the demand for managers? Using a rich firm-level data set that uniquely distinguishes between the compensations of managers and non-managers in the Indian manufacturing sector, and exploiting the exogenous nature of India's Eight-Plan trade reform, we investigated the potential causal link between inputtrade liberalization and the demand for managers relative to non-managers. A preliminary analysis showed that trade liberalization interacts with the relative demand for managers through imports, and more specifically, through those of intermediate inputs - motivating our focus on changes in input tariff.

\footnotetext{
${ }^{63}$ While it is plausible to assume that managers are skilled, it is not the case that all the skilled are managers; some will inevitably be non-managers. This is further observed via the relatively low correlation between our the industry-level measures of skill intensity and the demand for managers noted previously.
} 
The main analysis established a causal link: decreases in input tariffs increase the relative demand for managers in a remarkably robust and persistent way that is also economically meaningful; a $10 \%$ decrease in input tariffs increases the compensation share of managers by approximately $1-1.5 \%$, via increases in the number as well as average wages and bonuses of managers. Interestingly, this result is not a direct outcome of potential connections between managers and skill, productivity, capital intensity, export tariffs, or management technology. Further investigations identified the input-importing domestically owned firms that produce intermediate goods as those that trigger the result. These patterns were: (i) observed across the firms' size distribution; (ii) applicable in both exporting and non-exporting firms; (iii) stronger in family-run firms that operate under flexible labor market regulations; (iv) relatively more dominant in the short-run. In addition, we showed that unlike changes in input tariffs, import competition does not affect the relative demand for managers.

The results of this study have various implications. Policy-wise, given the established connection between better management technology and productivity, our results highlight the potential significance that trade liberalization may have in this, most notably that in intermediate inputs. In addition, the paper stresses the need to study the dynamics of firms in developing economies within the context of organizational structure and globalization, calling for further research on the topic. 


\section{References}

Acemoglu, D. (2003): "Patterns of Skill Premia," Review of Economic Studies, 70(2), 199-230.

Acemoglu, D., P. Aghion, C. Lelarge, and J. Van Reenen (2007): "Technology, Information and the Decentralization of the Firm," Quarterly Journal of Economics, 122(4), 1759-1799.

Acemoglu, D., D. Autor, D. Dorn, G. Hanson, and B. Price (2016): "Import Competition and the Great US Employment Sag of the 2000s," Journal of Labor Economics, 34(1), 141-198.

Acemoglu, D., and F. Zilibotti (2001): "Productivity Differences," Quarterly Journal of Economics, 116(2), 563-606.

Aghion, P., R. Burgess, S. Redding, and F. Zilibotti (2008): "The Unequal Effects of Liberalization: Evidence from Dismantling the License Raj in India," American Economic Review, 98(4), 1397-1412.

Ahsan, R. (2013): "Input Tariffs, Speed of Contract Enforcement, and the Productivity of Firms in India," Journal of International Economics, 90(1), 181-192.

Ahsan, R., And D. Mitra (2014): “Trade Liberalization and Labor's Slice of the Pie: Evidence from Indian Firms," Journal of Development Economics, 108(1), 1-16.

Allcott, H., A. Collard-Wexler, and S. D. O'Connell (2016): "How Do Electricity Shortages Affect Productivity? Evidence from India," American Economic Review, 106(3), 587-625.

Amiti, M., And J. Konings (2007): "Trade liberalization, intermediate inputs, and productivity: Evidence from Indonesia," American Economic Review, 97(5), 1611-1638.

Arellano, B., And S. Bond (1991): "Some Tests of Specification for Panel Data: Monte Carlo Evidence and an Application to Employment Equations," Review of Economic Studies, 58(2), $277-297$.

Autor, D., D. Dorn, and G. Hanson (2013): "The China Syndrome: Local Labor Market Effects of Import Competition in the United States," American Economic Review, 103(6), 21212168.

Bandiera, O., R. Lemos, A. Prat, and R. Sadun (2017): "Managing the Family Firm: Evidence from CEOs at Work," Review of Financial Studies, forthcoming. 
BAs, M. (2012): "Input-Trade Liberalization and Firm Export Decisions: Evidence from Argentina," Journal of Development Economics, 97(2), 481-493.

Bas, M., And A. Berthou (2017): "Does Input-Trade Liberalization Affect FirmsŠ Foreign Technology Choice?," World Bank Economic Review, 31(2), 351-384.

Bas, M., A. Johansson, F. Murtin, and G. Nicoletti (2016): "The Effects of Input Tariffs on Productivity: Panel Data Evidence for OECD Countries," Review of World Economics, 152(2), 401-424.

Bas, M., and V. Strauss-Kahn (2014): "Does Importing More Inputs Raise Exports? FirmLevel Evidence from France," Review of World Economics, 150(2), 241-275.

(2015): "Input-Trade Liberalization, Export Prices and Quality Upgrading," Journal of International Economics, 95(2), 250-262.

Berman, E., J. Bound, and Z. Griliches (1994): "Changes in the Demand for Skilled Labor Within U.S. Manufacturing: Evidence from the Annual Survey of Manufactures," Quarterly Journal of Economics, 109(2), 367-397.

Besley, T., and R. Burgess (2004): "Can Labor Regulation Hinder Economic Performance? Evidence from India," Quarterly Journal of Economics, 19 (1), 91-134.

Bhattacharjea, A. (2006): "Labour Market Regulation and Industrial Performance in India: A Critical Review of the Empirical Evidence," Indian Journal of Labour Economics, 49, 211-232.

Bloom, N., E. Brynjolfsson, L. Foster, R. Jarmin, I. SAporta-Eksten, and J. Van Reenen (2013): "Management in America," CES Working Paper 2013-01.

Bloom, N., M. Draca, and J. Van Reenen (2016): "Technical Change: The Impact of Chinese Imports on Innovation, Diffusion and Productivity," Review of Economic Studies, 83(1), 87-117.

Bloom, N., B. Eifert, A. Mahajan, D. McKenzie, and J. Roberts (2013): "Does Management Matter? Evidence from India," Quarterly Journal of Economics, 128(1), 1-51.

Bloom, N., L. Garicano, R. Sadun, and J. Van Reenen (2014): "The Distinct Effects of Information Technology and Communication Technology on Firm Organization," Management Science, forthcoming.

Bloom, N., R. Lemos, R. Sadun, D. Scur, and J. Van Reenen (2014): "The New Empirical Economics of Management," Journal of the European Economics Association, 12(4), 835-876. 
Bloom, N., K. Manova, S. Sun, J. Van Reenen, and Z. Yu (2016): "Managing Trade: Evidence from China and the US," Mimeo.

Bloom, N., R. Sadun, and J. Van Reenen (2010): "Does Product Market Competition Lead Firms to Decentralize?," American Economic Review, Papers and Proceedings, 100, 434Ü438.

Bloom, N., and J. Van Reenen (2007): "Measuring and Explaining Management Practices Across Firms and Countries," Quaterly Journal of Economics, 122(4), 1351-1408.

(2010): "Why Do Management Practices Differ across Firms and Countries?," Journal of Economic Perspectives, 24(1), 203-224.

Bonfatti, R., and M. Ghatak (2013): "Trade and the Allocation of Talent with Capital Market Imperfections," Journal of International Economics, 89(1), 187-201.

Burstein, A., J. Cravino, and J. Vogel (2013): "Capital-Skill Complementarity and the Skill Premium in a Quantitative Model of Trade," American Economic Journal: Macroeconomics, $5(2), 32-71$.

Caliendo, L., F. Monte, and E. Rossi-Hansberg (2015): "The Anatomy of French Production Hierarchies," Journal of Political Economy, 123(4), 809-852.

Caliendo, L., and E. Rossi-Hansberg (2012): "The Impact of Trade on Organization and Productivity," Quarterly Journal of Economics, 127(3), 1393-1467.

Carpenter, M. A., and W. G. Sanders (1998): "Internationalization and Firm Governance: The Roles of CEO Compensation, Top Team Composition, and Board Structure," Academy of Management Journal, 41(2), 158-178.

Caselli, F., And D. J. Wilson (2004): "Importing Technology," Journal of Monetary Economics, $51(1), 1-32$.

Chamarbagwala, R., and G. Sharma (2011): "Industrial de-licensing, trade liberalization, and skill upgrading in India," Journal of Development Economics, 96(2), 314-336.

Chaurey, R. (2015): "Labor Regulations and Contract Labor Use: Evidence from Indian Firms," Journal of Development Economics, 114, 224-232.

Chen, C. (2017): "Management Quality and Firm Hierarchy in Industry Equilibrium," American Economic Journal: Microeconomics, forthcoming. 
Chen, C., and C. Steinwender (2017): "Import Competition, Heterogeneous Preferences of Managers, and Productivity," Mimeo.

Cunat, V., and M. Guadalupe (2009): "Globalization and the Provision of Incentives inside the Firm," Journal of Labor Economics, 27(2), 179-212.

De Loecker, J., P. Goldberg, A. Khandelwal, and N. Pavcnik (2016): "Prices, Markups and Trade Reform," Econometrica, 84(2), 445-510.

Debroy, B., and A. T. Santhanam (1993): "Matching Trade Codes with Industrial Codes," Foreign Trade Bulletin, XXIV(1), 5-27.

Eaton, J., and S. Kortum (1996): "Trade in Ideas Patenting and Productivity in the OECD," Journal of International Economics, 40(4), 251-278.

Eaton, J., And S. Kortum (2001): "Trade in Capital Goods," European Economic Review, 45(7), 1195-1235.

Fernandes, P. A., P. Ferreira, and L. A. Winters (2014): "The Effect of Competition on ManagersS̆ Compensation: Evidence from a Quasi-natural Experiment," Journal of Human Resources, forthcoming.

Friedrich, B. (2016): "Trade Shocks, Firm Hierarchies and Wage Inequality," Mimeo.

Garicano, L. (2000): "Hierarchies and the Organization of Knowledge in Production," Journal of Political Economy, 108(5), 874-904.

Garicano, L., and E. Rossi-Hansberg (2004): "Inequality and the Organization of Knowledge," American Economic Review, 94(2), 197-202.

- (2006): "Organization and Inequality in a Knowledge Economy," Quarterly Journal of Economics, 121(4), 1383-1435.

- (2012): "Organizing Growth," Journal of Economic Theory, 147(2), 623-656.

Ghosh, S. (2014): "Manufacturing Sector in India: Role of External Economies and Industrial Policy," Mimeo.

Goldberg, P., and N. Pavcnik (2016): "The Impact of Trade Policy," in Staiger, B. and K. Bagwell (eds.), the Handbook of Commercial Policy, Volume 1A, Elsevier, pp. 161-206. 
Goldberg, P. K., A. K. Khandelwal, N. Pavcnik, and P. Topalova (2010): "Imported Intermediate Inputs and Domestic Product Growth: Evidence from India," Quarterly Journal of Economics, 125(4), 1727-1767.

GoldberG, P. K., and N. Pavcnik (2007): "Distributional Effects of Globalization in Developing Countries," Journal of Economic Literature, 45(1), 39-82.

Griliches, Z. (1969): "Capital-Skill Complementarity," Review of Economics and Statistics, $51(4), 465-468$.

Guadalupe, M., and J. Wulf (2010): "The Flattening Firm and Product Market Competition: The Effect of Trade Liberalization on Corporate Hierarchies," American Economic Journal: Applied Economics, 2(4), 105-127.

Gupta, P., R. Hasan, and U. Kumar (2009): "Big Reforms but Small Payoffs: Explaining the Weak Record of Growth in Indian Manufacturing," India Policy Forum, 5, 2008-09.

Halpern, L., M. Koren, and A. Szeidl (2015): "Imported Inputs and Productivity," American Economic Review, 105(12), 3660-3703.

Hasan, R., D. Mitra, P. Ranjan, and R. Ahsan (2012): "Trade liberalization and unemployment: Theory and evidence from India," Journal of Development Economics, 97(2), 269-280.

Hsieh, C., And P. Klenow (2009): "Misallocation and Manufacturing TFP in China and India," Quarterly Journal of Economics, 124(4), 1403-1448.

Kasahara, H., and B. Lapham (2013): "Productivity and the Decision to Import and Export: Theory and Evidence," Journal of International Economics, 89(2), 297-316.

Keller, W., And W. Olney (2017): “Globalization and Executive Compensation,” NBER Working Paper 23384.

Krusell, P., L. E. Ohanian, J.-V. Rios-Rull, and G. L. Violante (2000): "Capital-Skill Complementarity and Inequality: A Macroeconomic Analysis," Econometrica, 68(5), 1029-1053.

Larrain, M. (2015): “Capital Account Opening and Wage Inequality," Review of Financial Studies, 28(6), 1555-1587.

Levinsohn, J., And A. Petrin (2003): "Estimating Production Functions Using Inputs to Control for Unobservables," Review of Economic Studies, 70(2), 317-341. 
MA, L. (2015): "Globalization and Top Income Shares," Miemo.

Marin, D. (2009): "The Battle for Talent: Globalisation and the Rise of Executive Pay," Bruegel Working Paper 2009-01.

Marin, D., And T. Verdier (2003): "Globalization and the New Enterprise," Journal of the European Economic Association, 1(2-3), 337-344.

- (2008): "Power Inside the Firm and the Market: A General Equilibrium Approach," Journal of the European Economic Association, 6(4), 752-788.

- (2014): "Corporate Hierarchies and International Trade: Theory and Evidence," Journal of International Economics, 94(2), 295-310.

McCaig, B., and N. Pavcnik (2014): "Export Markets and Labor Reallocation in a Poor Country," NBER Working Paper 22045.

(2015): "Informal employment in a growing and globalizing low-income country," American Economic Review Papers and Proceedings, 105, 545-550.

Michaels, G., A. Natraj, and J. Van Reenen (2014): "Has ICT Polarized Skill Demand? Evidence from Eleven Countries over 25 Years," Review of Economics and Statistics, 96(1), $60-77$.

Mion, G., And L. D. Opromolla (2014): "Managers' Mobility, Trade Performance, and Wages," Journal of International Economics, 94(1), 85-101.

Nataraj, S. (2011): “The Impact of Trade Liberalization on Productivity: Evidence from India's Formal and Informal Manufacturing Sectors," Journal of International Economics, 85(2), 292301.

Nouroz, H. (2001): Protection in Indian Manufacturing. MacMillan Publishers, MacMillan India Ltd., India.

OECD (2007): "OECD Economic Surveys: India," Volume 2007, Issue no. 14.

Oxelheim, L., And T. Randy (2005): "The Effects of Internationalization on CEO Compensation," Journal of International Business Studies, 36(4), 470-483.

PArro, F. (2013): "Capital-skill complementarity and the skill premium in a quantitative model of trade," American Economic Journal: Macroeconomics, 5(2), 72-117. 
Patnaik, M. (2014): "Tax, Lies and Redtape," Mimeo.

Raveh, O., And A. Reshef (2016): "Capital Imports Composition, Complementarities, and the Skill Premium in Developing Countries," Journal of Development Economics, 118, 183-206.

Siddharth, S. (2008): "Capital Immobility and Regional Inequality : Evidence from India," World Bank Working Paper 47541.

Topalova, P. (2010): "Factor Immobility and Regional Impacts of Trade Liberalization: Evidence on Poverty from India," American Economic Journal: Applied Economics, 2(4), 1-41.

Topalova, P., and A. Khandelwal (2011): "Trade Liberalization and Firm Productivity: The Case of India," Review of Economics and Statistics, 93(3), 995-1009.

Verhoogen, E. A. (2008): "Trade, Quality Upgrading, and Wage Inequality in the Mexican Manufacturing Sector," Quarterly Journal of Economics, 123(2), 489-530.

ZeirA, J. (2007): "Wage Inequality, Technology, and Trade," Journal of Economic Theory, 137(1), 79-103.

Zhu, S. C., And D. Trefler (2005): "Trade and Inequality in Developing Countries: A General Equilibrium Analysis," Journal of International Economics, 65(1), 21-48. 


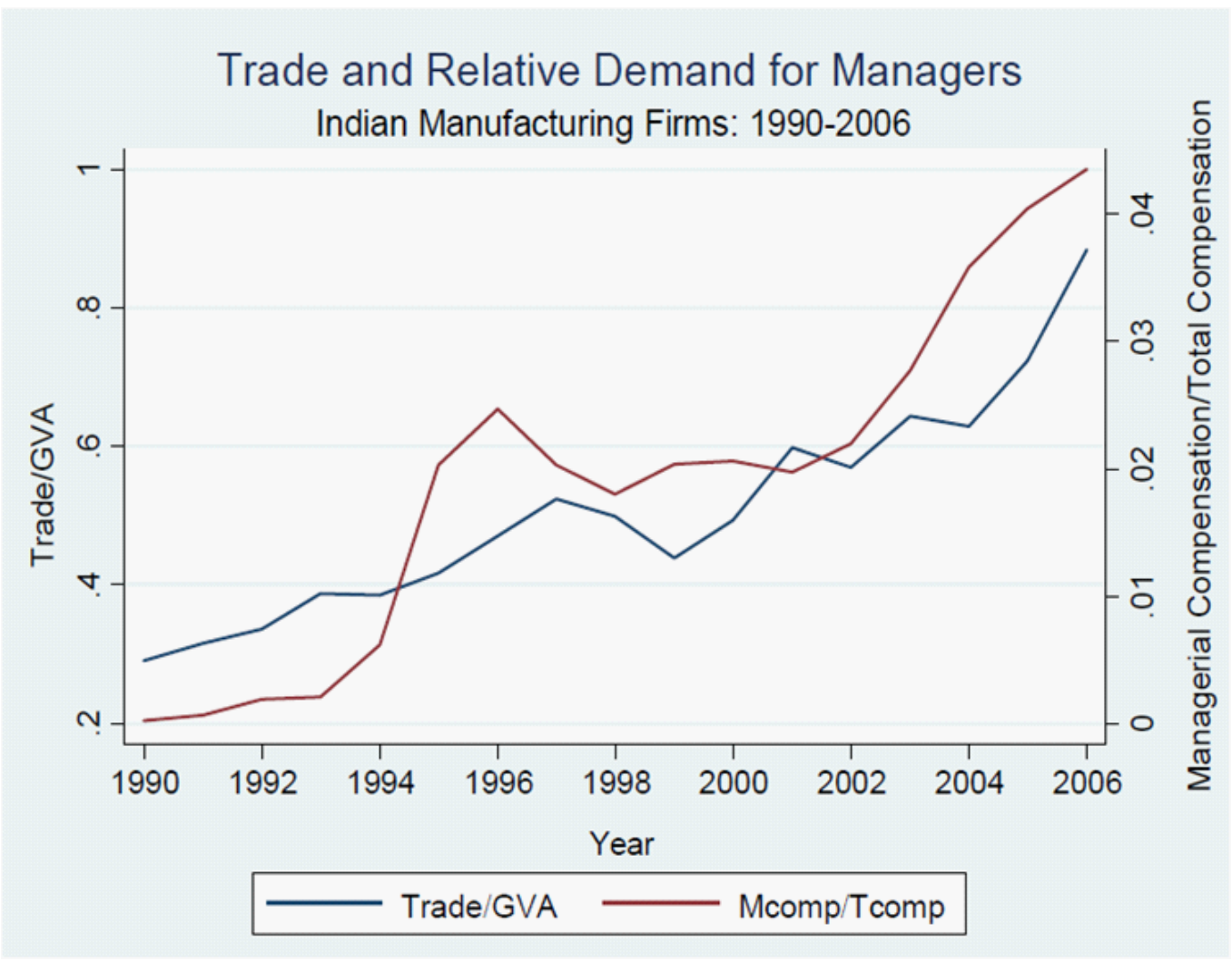

Figure 1: Trade and the Relative Demand for Managers

Notes: Figure presents the average GVA share of trade (exports plus imports) and the average compensation share of managers, 1990-2006 $(\rho=0.85)$ 


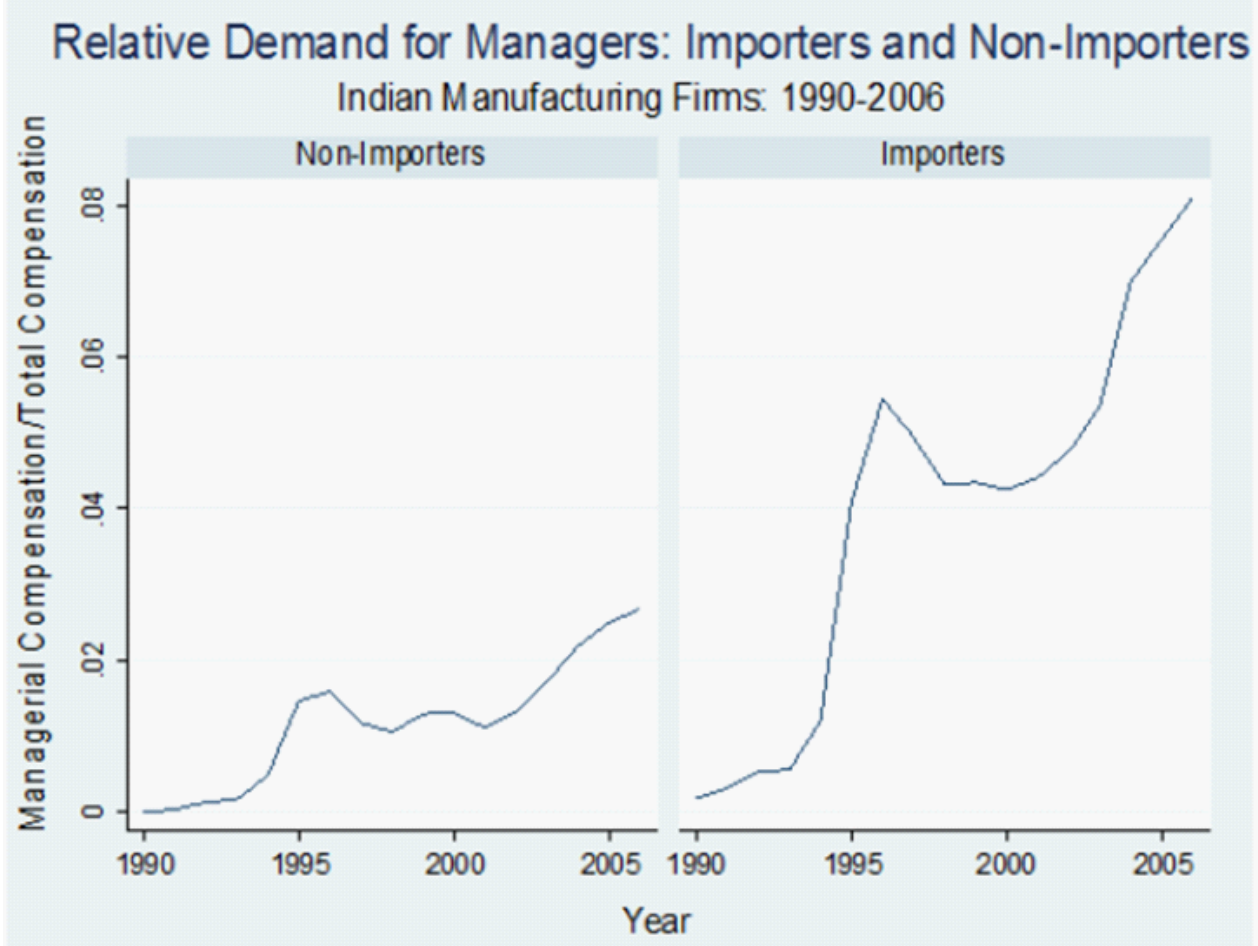

Figure 2: Relative Demand for Managers, Importers and Non-Importers, 1990-2006

Notes: Figure presents the average compensation share of managers' for importing and non-importing firms, 1990-2006 


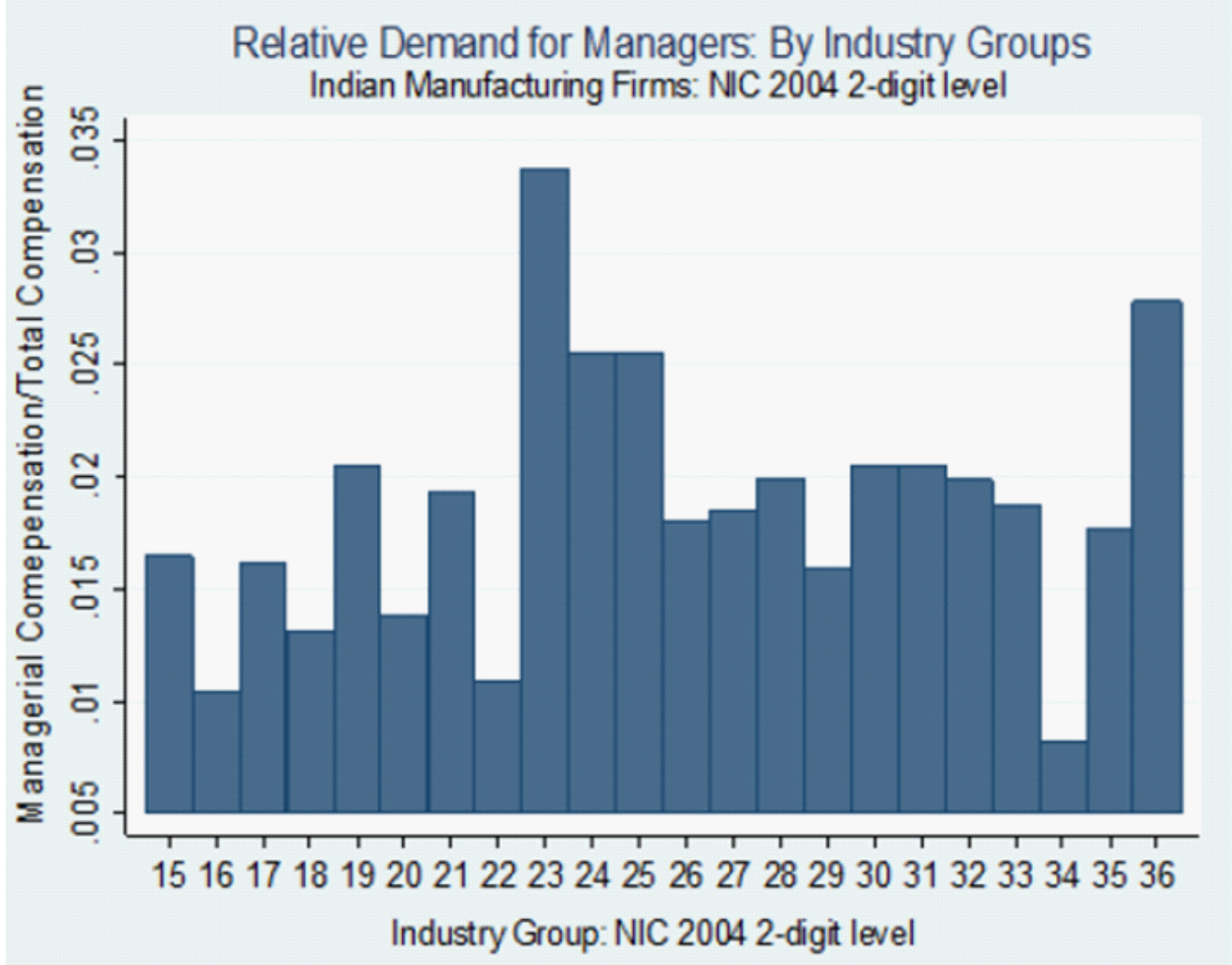

Figure 3: Average Compensation Share of Managers across Industries, 1990-2006 Notes: Figure presents the average compensation share of managers across NIC 2004 2-digit level industries, 1990-2006 


\section{Average Number of Executive Managers}

Indian Manufacturing Firms: 1990-2006

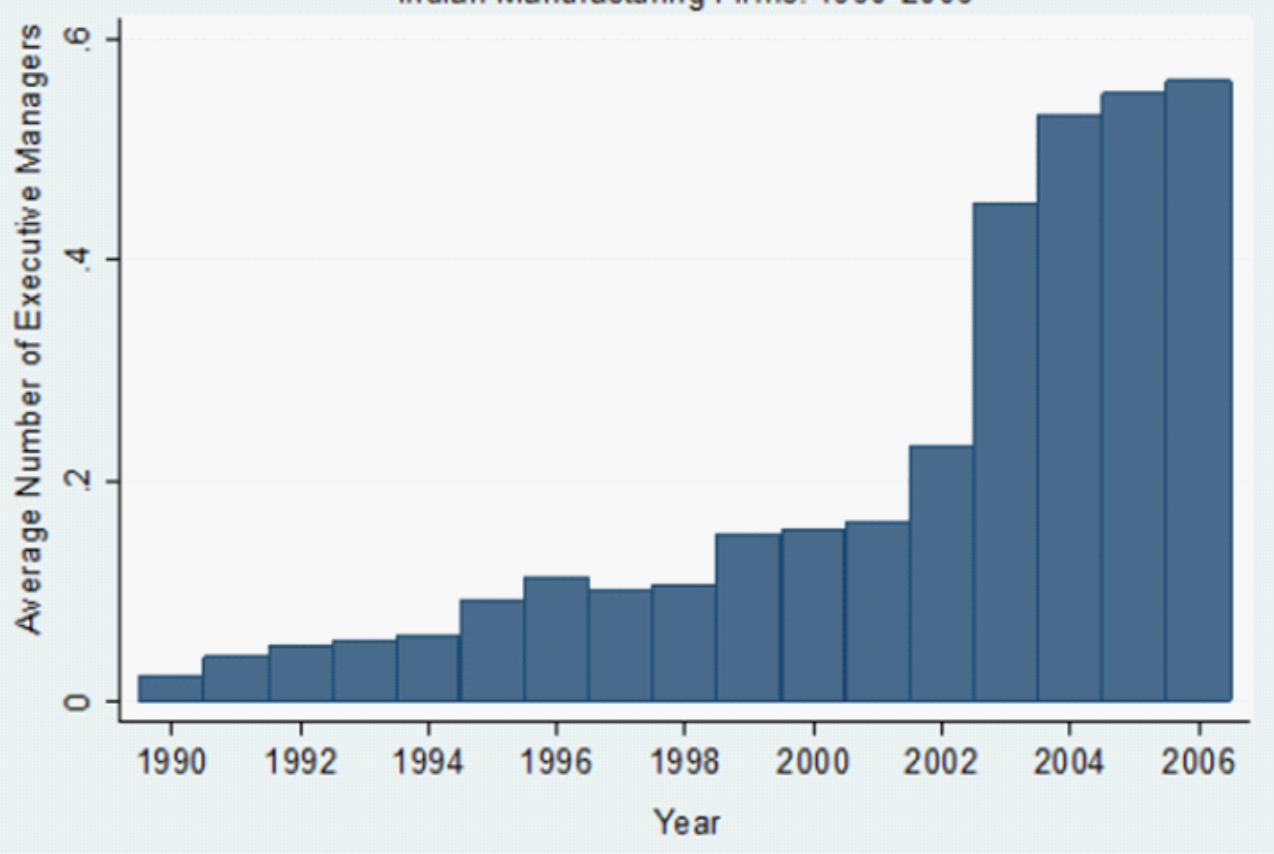

Figure 4: Average Number of Executive Managers, 1990-2006

Notes: Figure presents the average number of executive managers, 1990-2006 


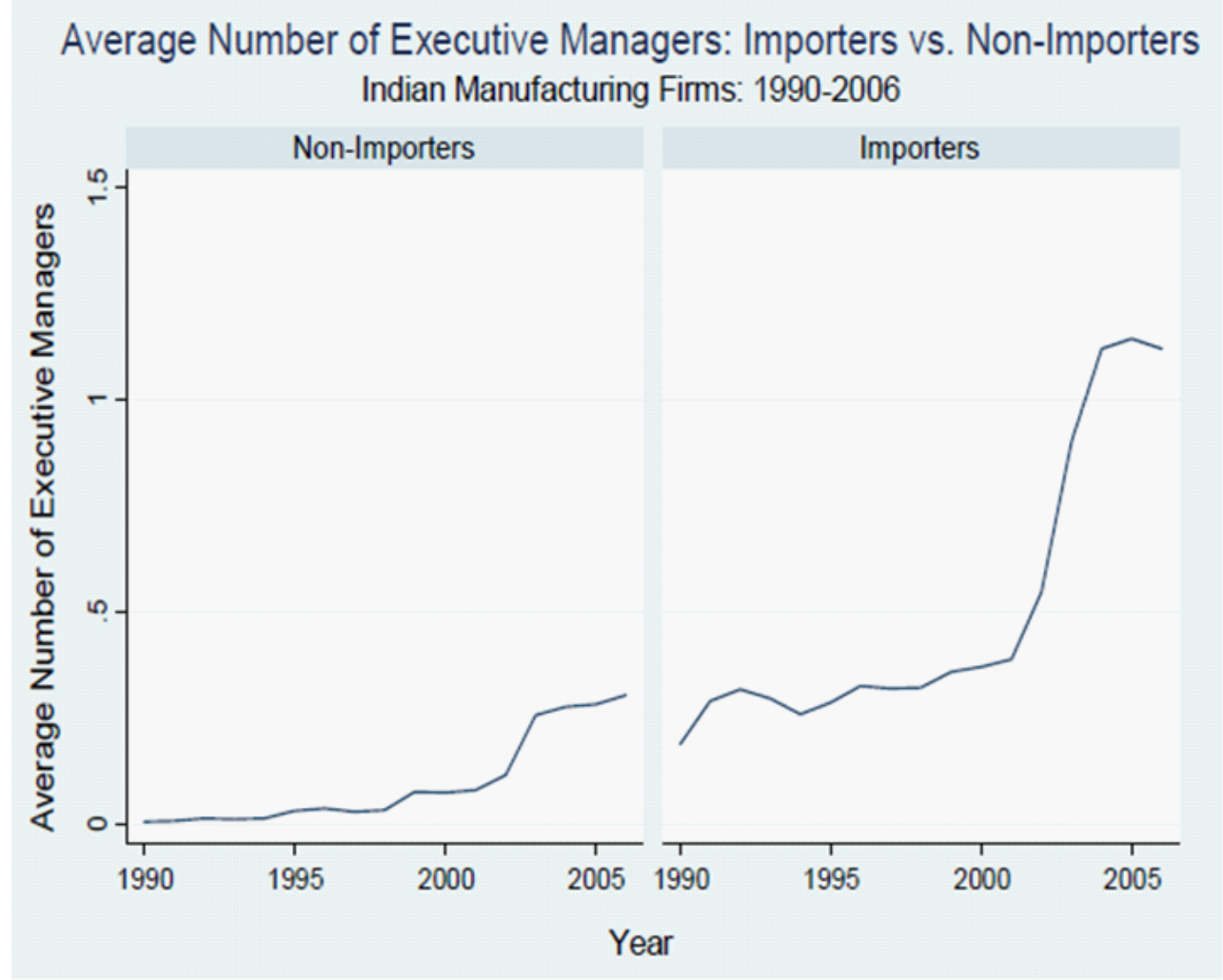

Figure 5: Average Number of Executive Managers, Importers and Non-Importers, 1990-2006 Notes: Figure presents the average number of executive managers for importing and non-importing firms, 1990-2006 
Table 1: Firms with Managerial Compensation VS. Firms without Managerial Compensation

\begin{tabular}{c|ccccc}
\hline \hline & Mean & Median & Std. Dev. & Min & Max \\
\hline Panel A: Firms & with Reported Managers' Compensation & \\
\hline R\&D intensity & 0.11 & 0.02 & 12.78 & 0 & 2163 \\
Capital Employed/GVA & 8.23 & 1.74 & 142.78 & 0 & 16789 \\
GVA & 1354.48 & 162.7 & 15604.67 & 0.1 & 931260 \\
\hline Panel B: Firms with & no Reported Managers' Compensation & \\
\hline R\&D intensity & 0.003 & 0 & 0.27 & 0 & 89.85 \\
Capital Employed/GVA & 2.17 & 0 & 43.67 & 0 & 7227 \\
GVA & 316.1 & 62.8 & 2458.59 & 0.1 & 130587
\end{tabular}

Notes: Panel A (B) covers firms that reported positive (zero) managerial compensation. 'R\&D intensity' is the GVA share of R\&D expenditure and royalty payments for technical knowhow. 'GVA' is gross value added, defined as total sales minus total raw material expenditure. 'Capital Employed' is the amount of capital employed. For further information on variables see data Appendix. 


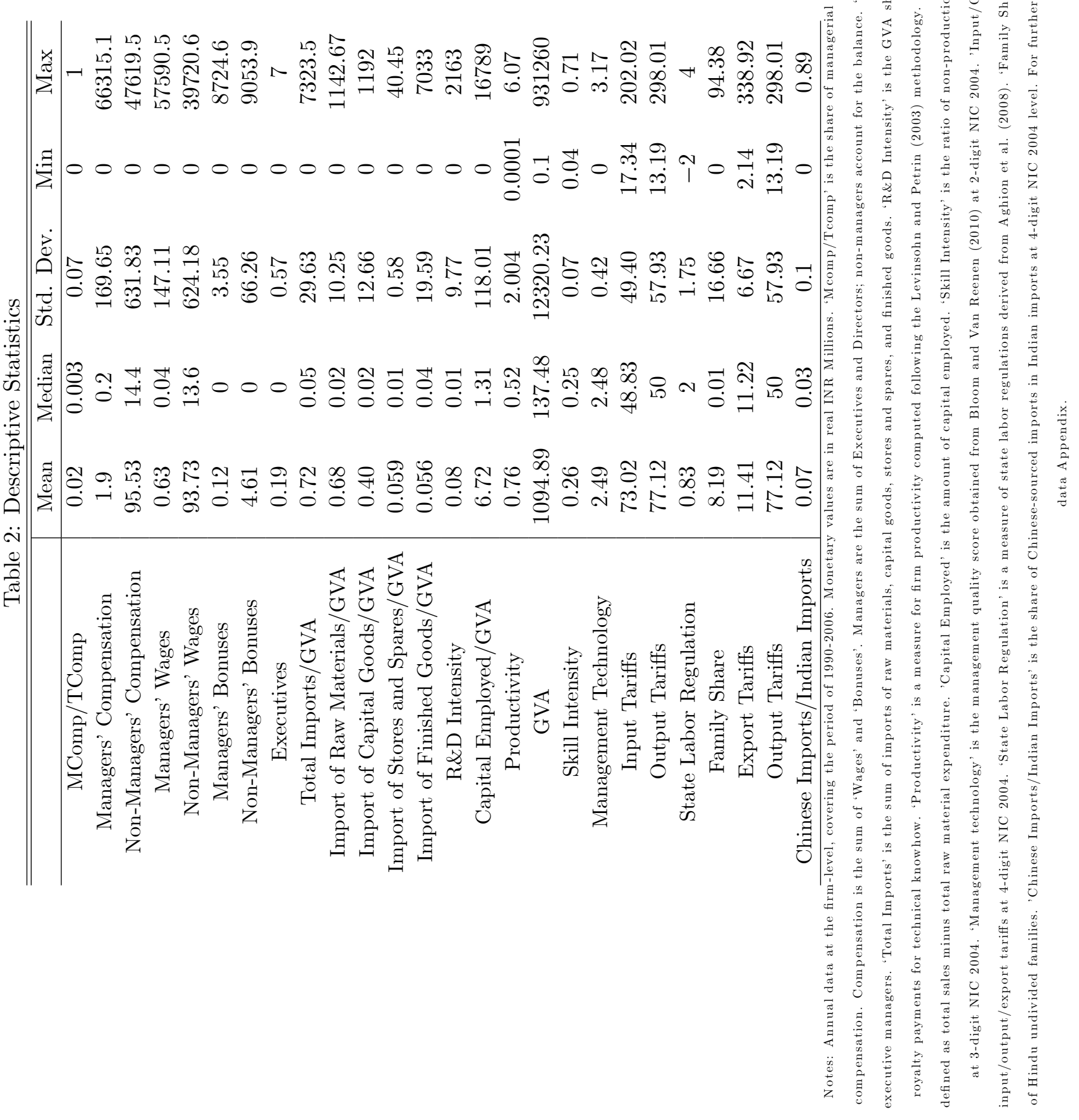









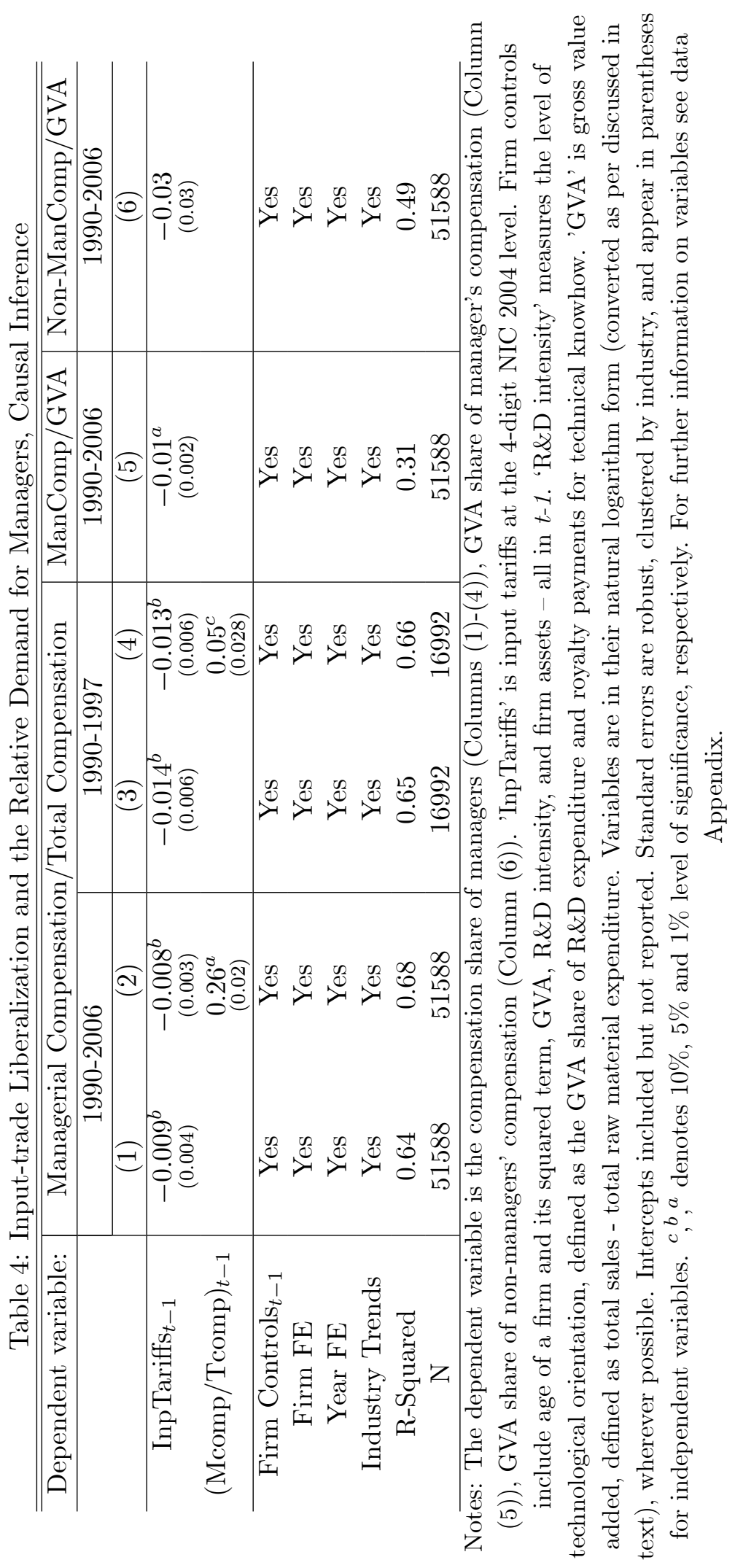




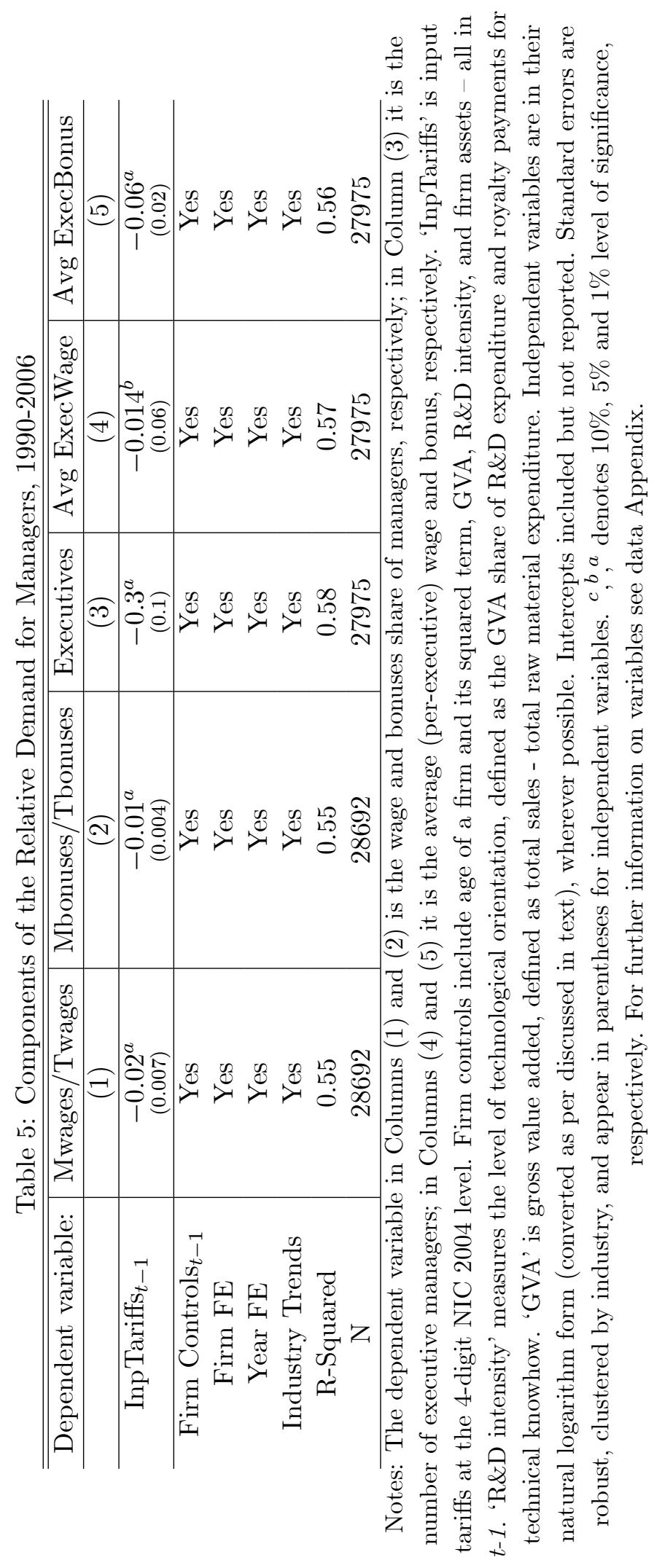




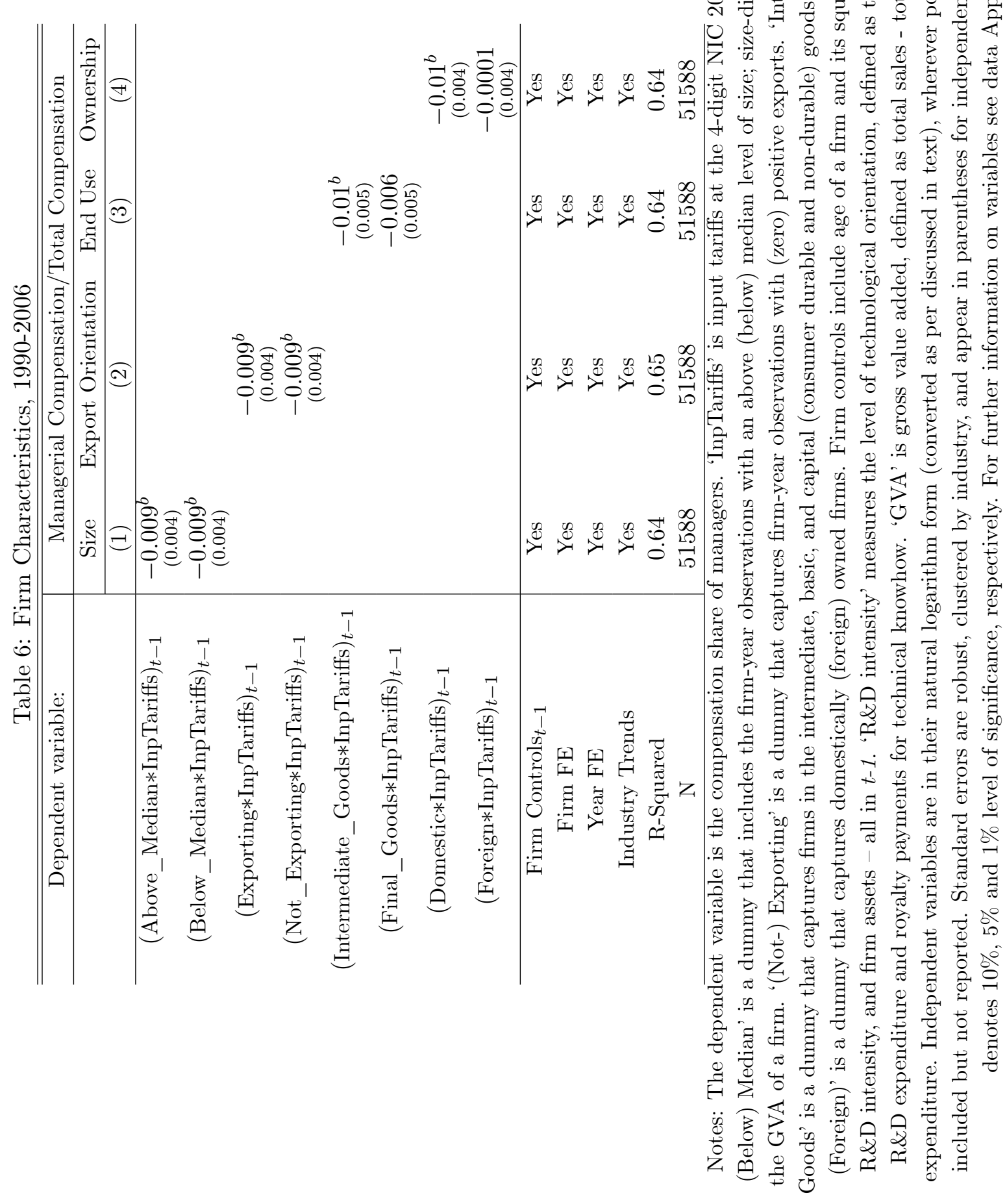




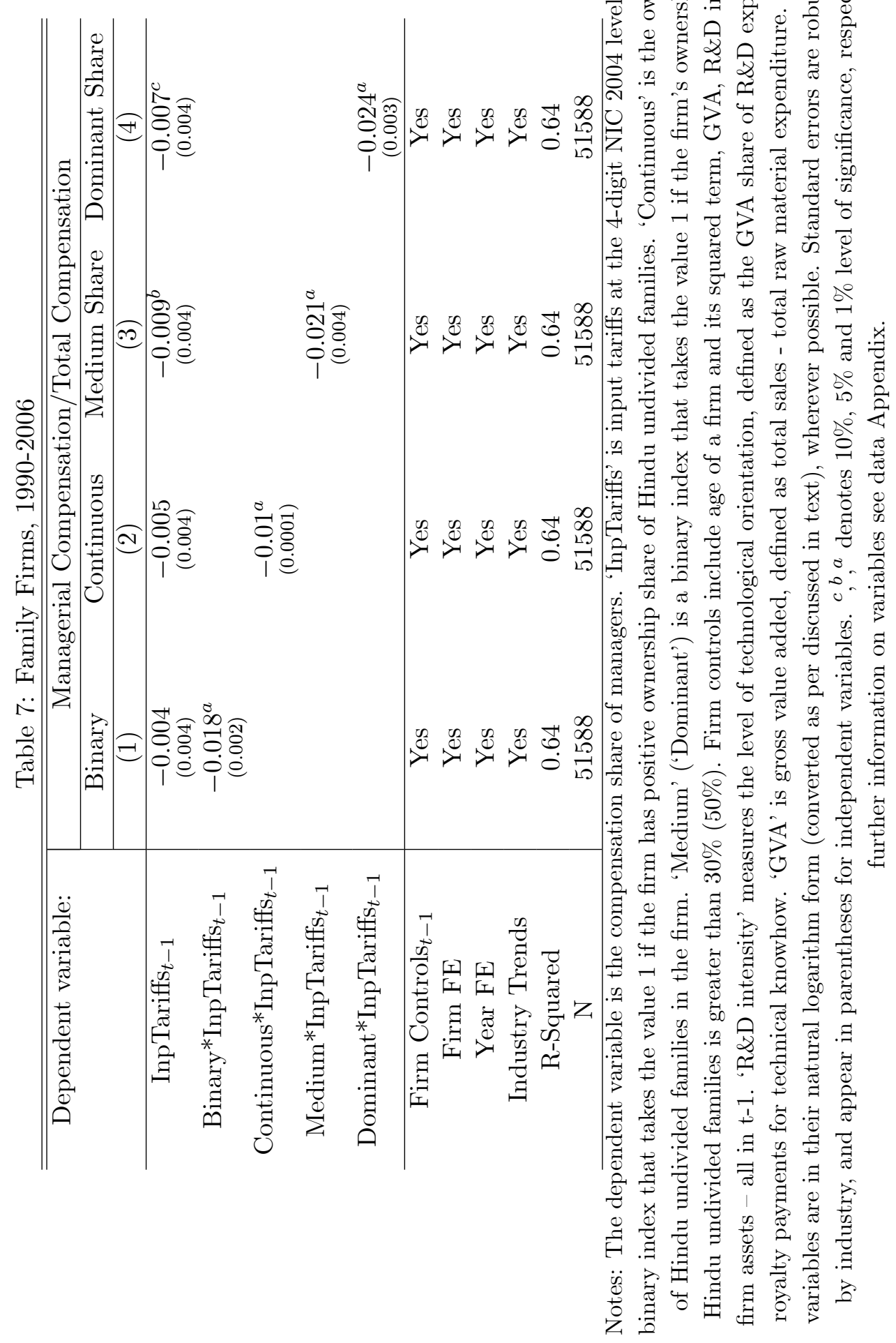



















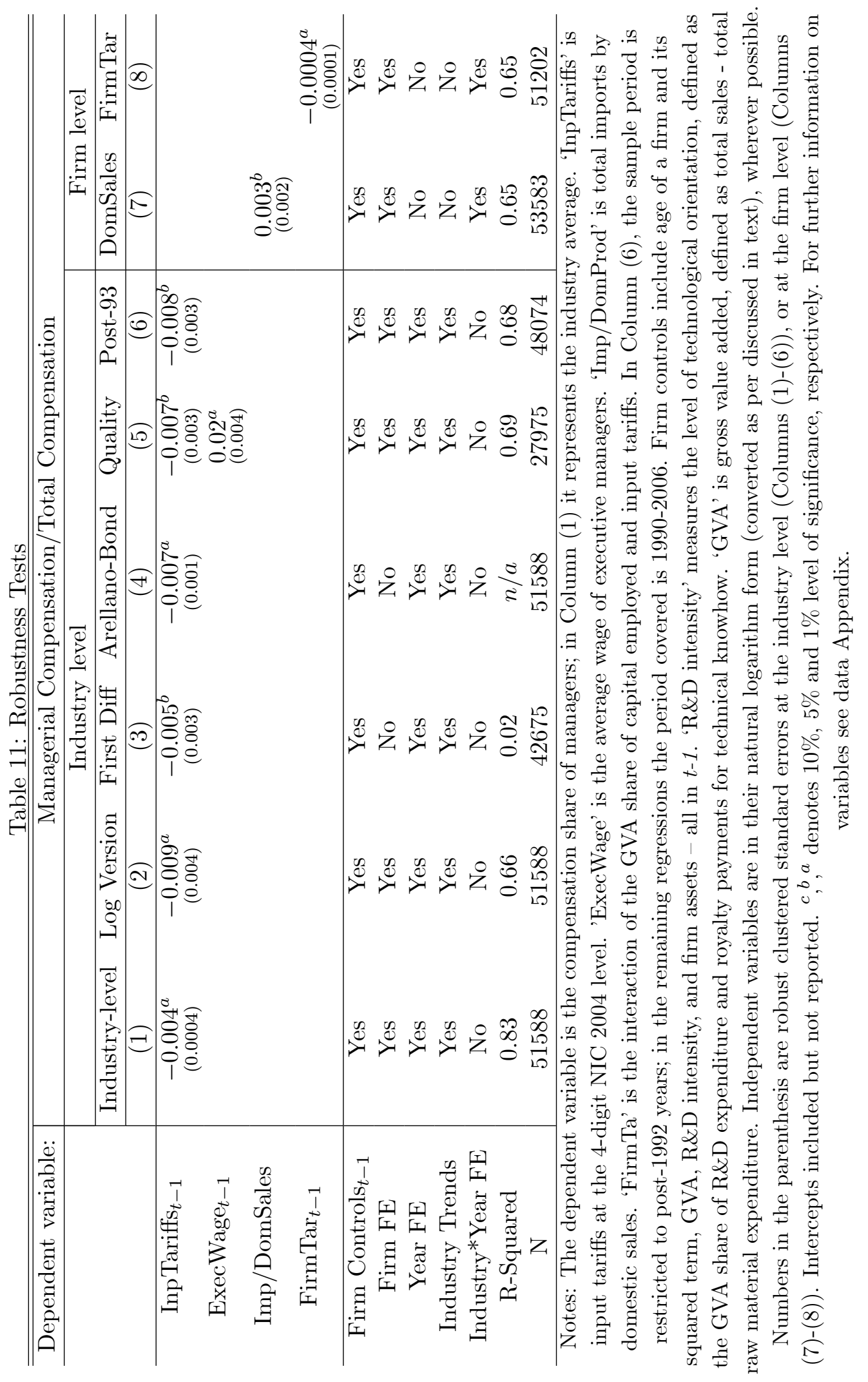


Online Appendix (for online publication)

\section{A Tables}




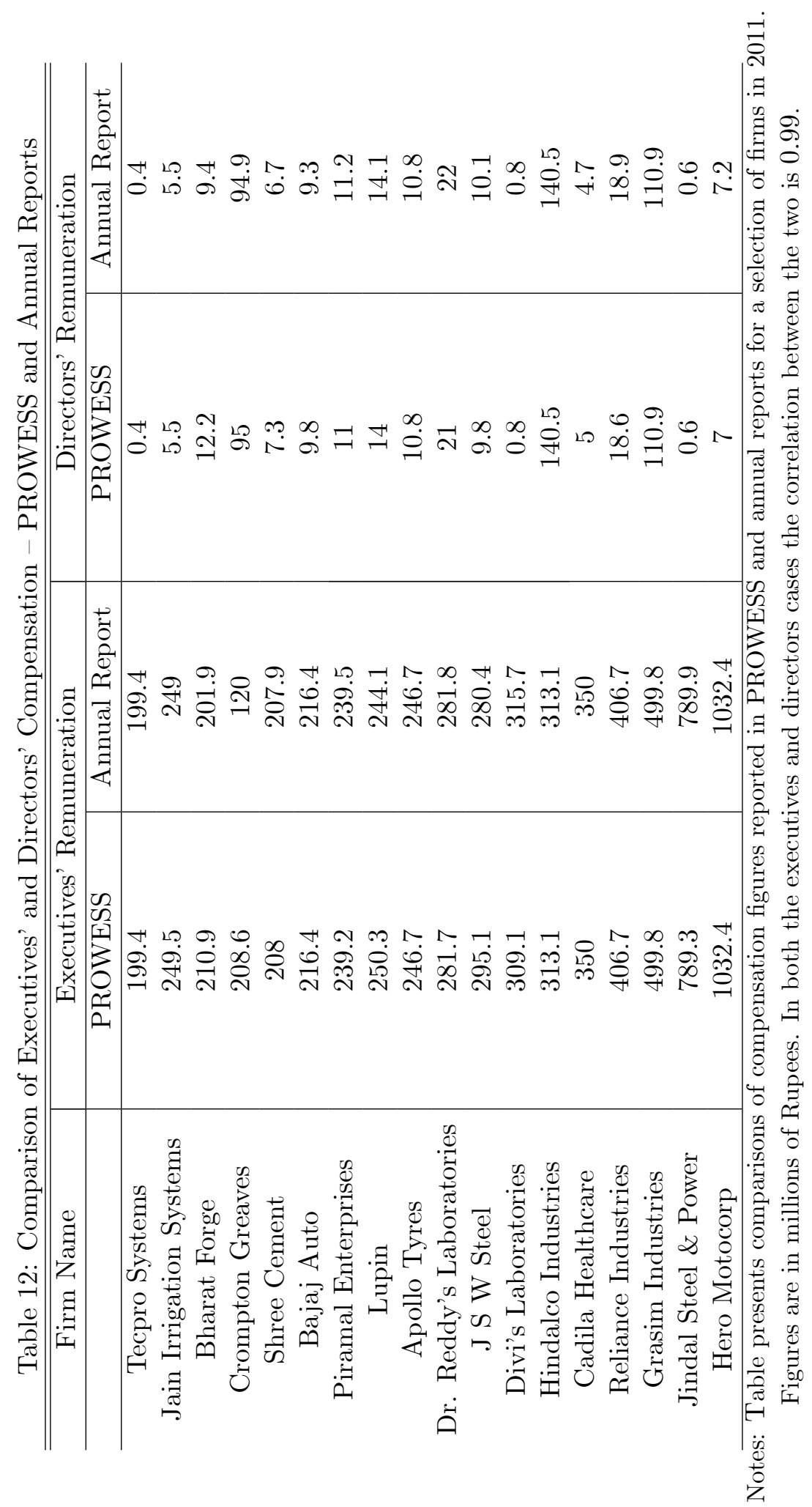




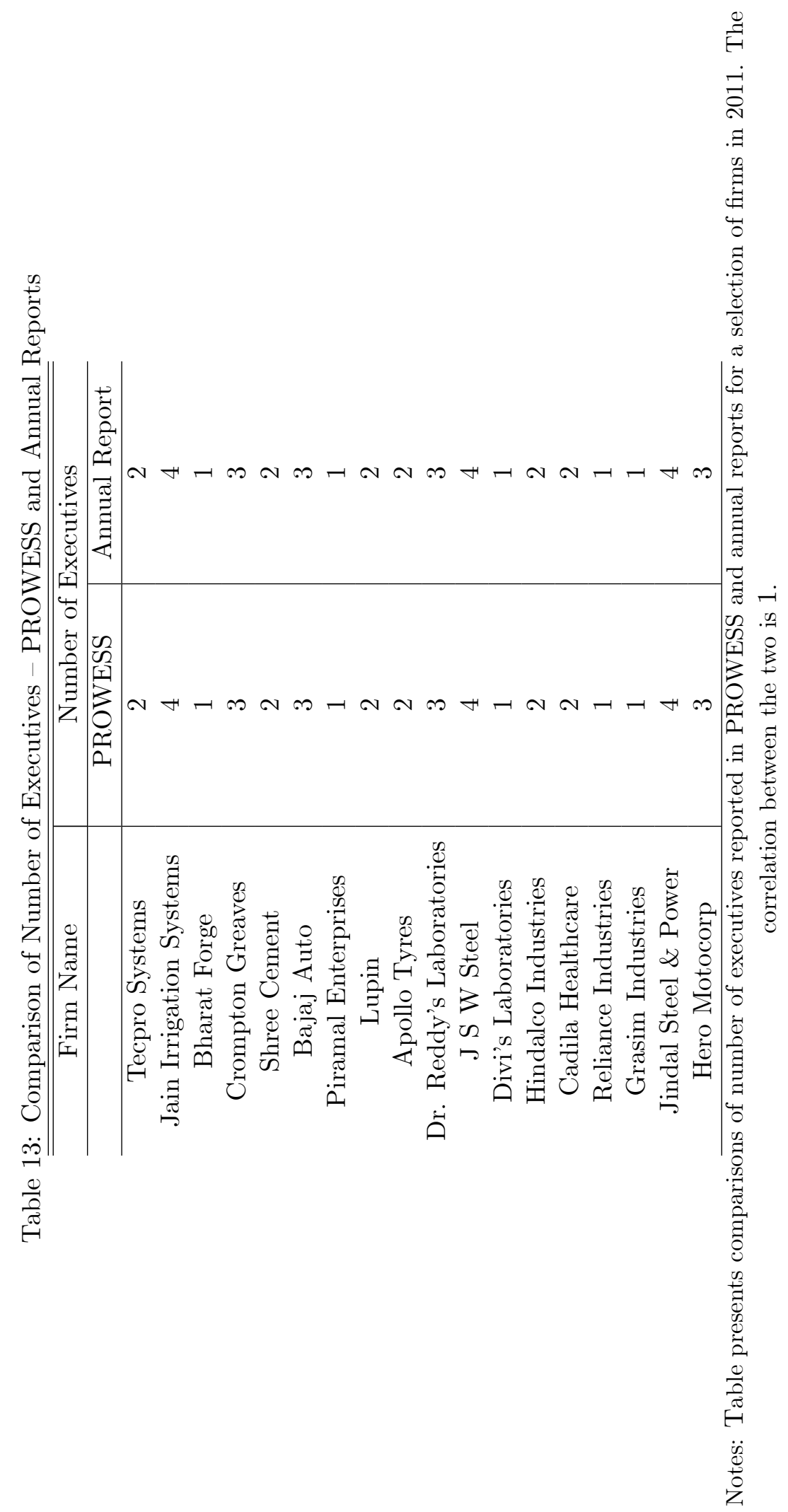




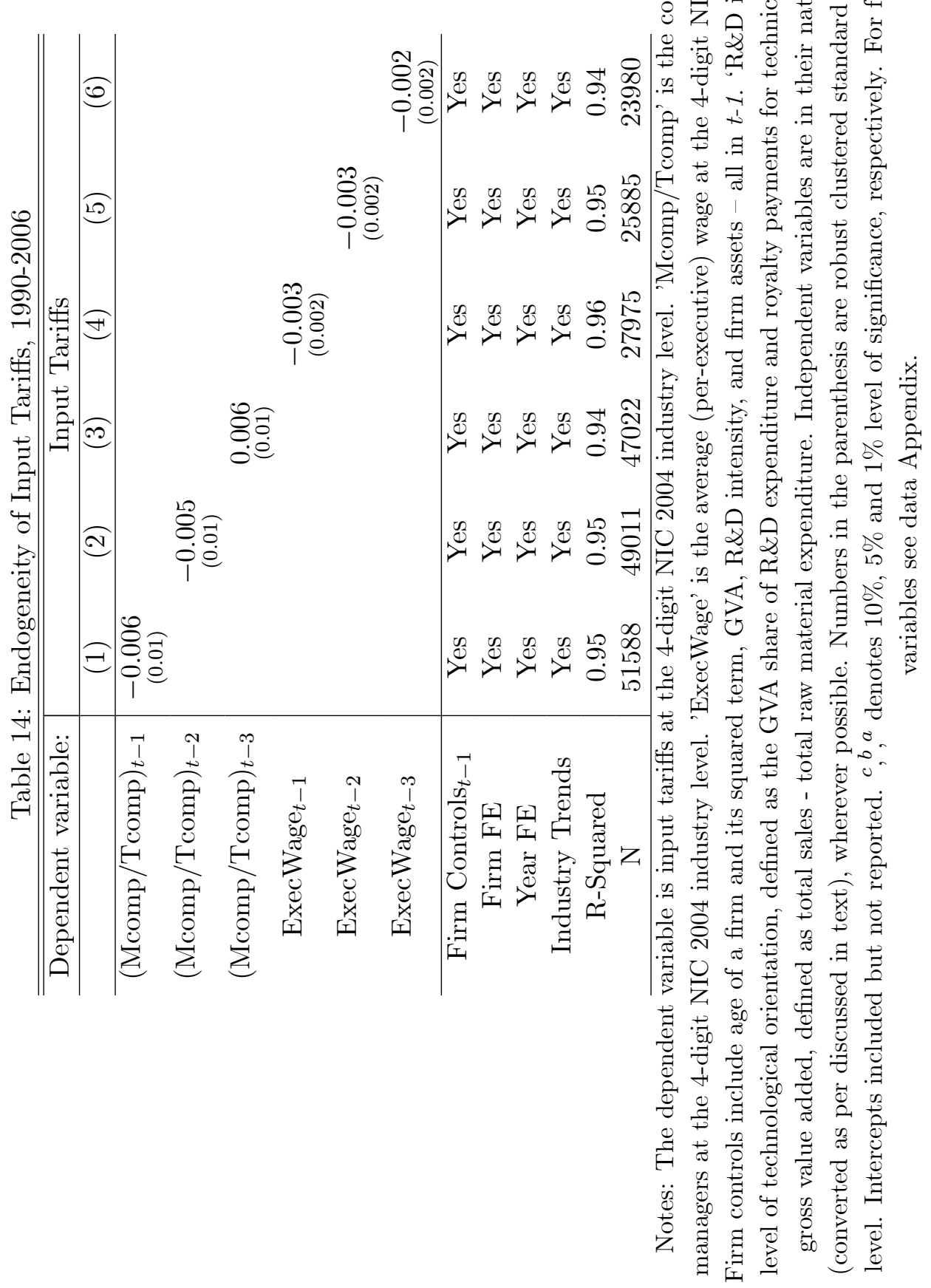

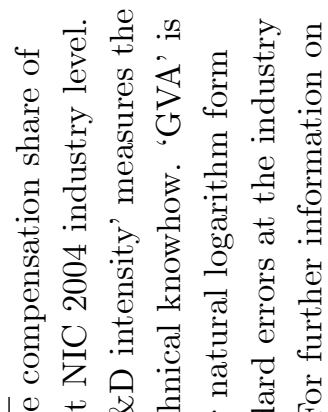

tric



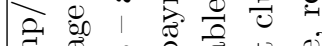



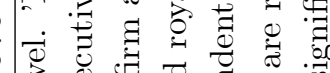

党

超



穴 4 in 0 का

若

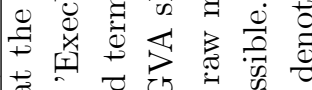

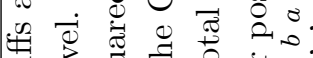

范

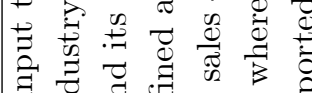

.. ब



乙 0.0 目

\% 0 ठ

I శే 过

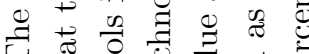

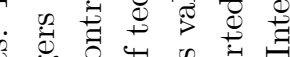

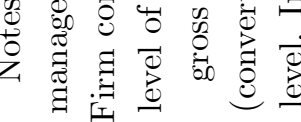




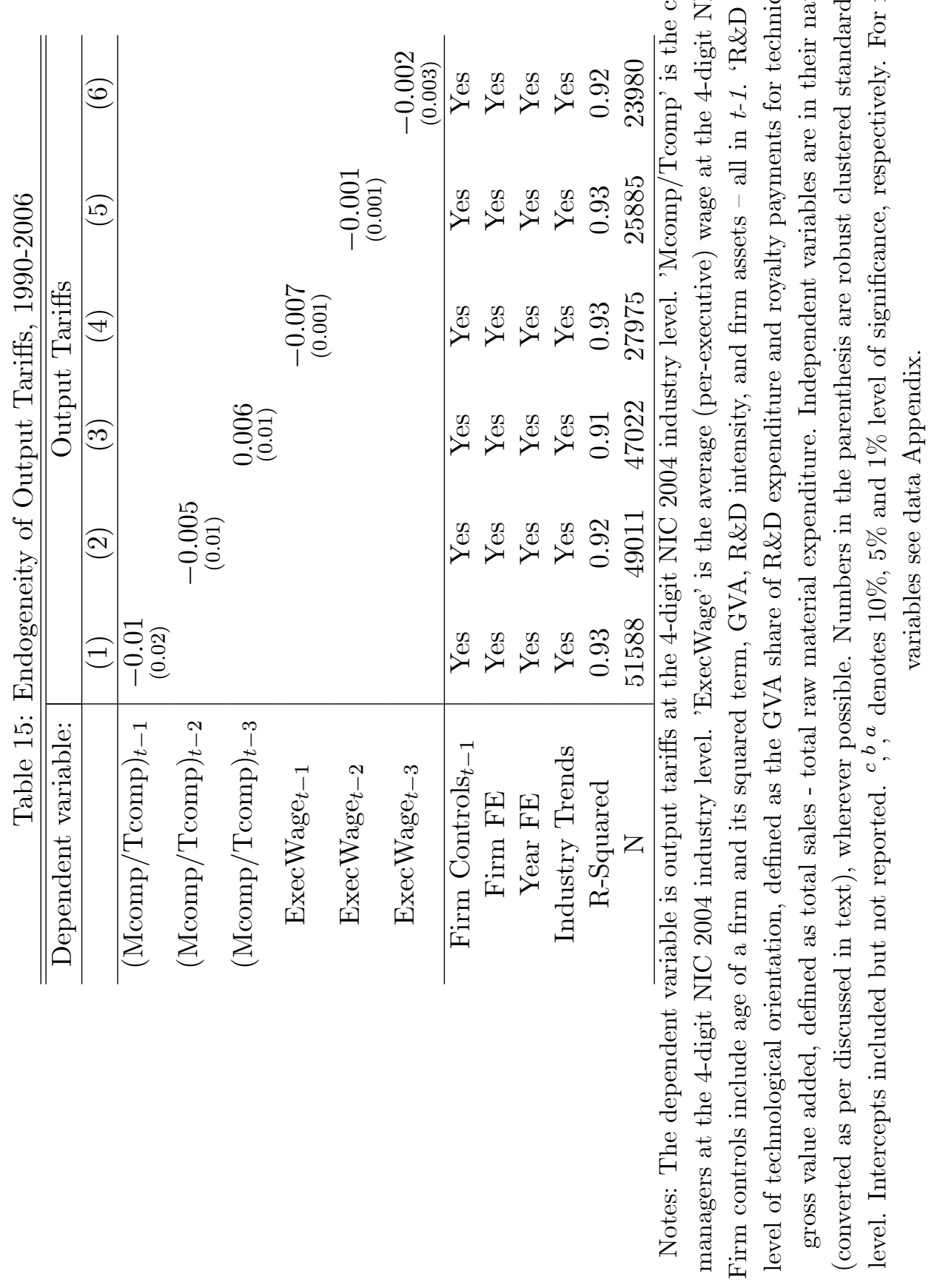
















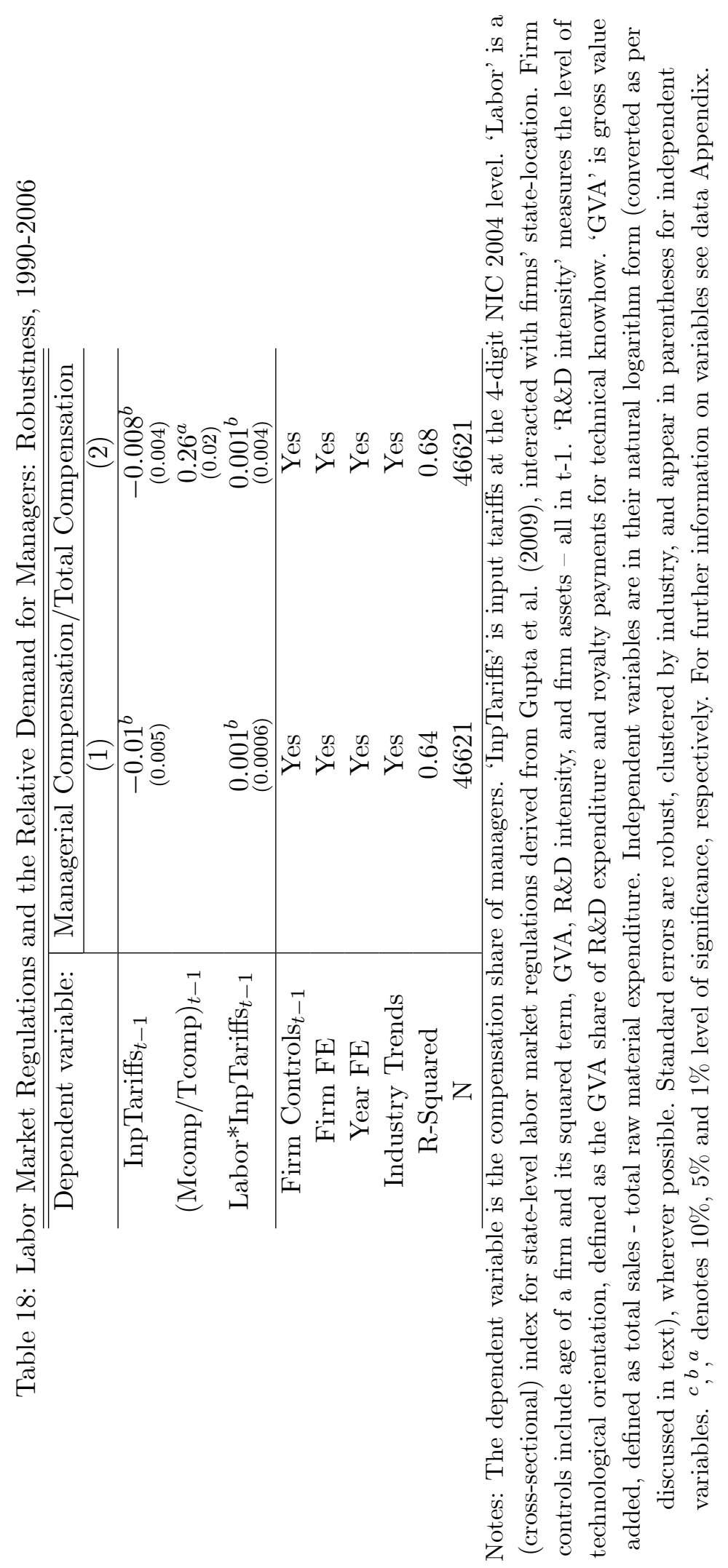




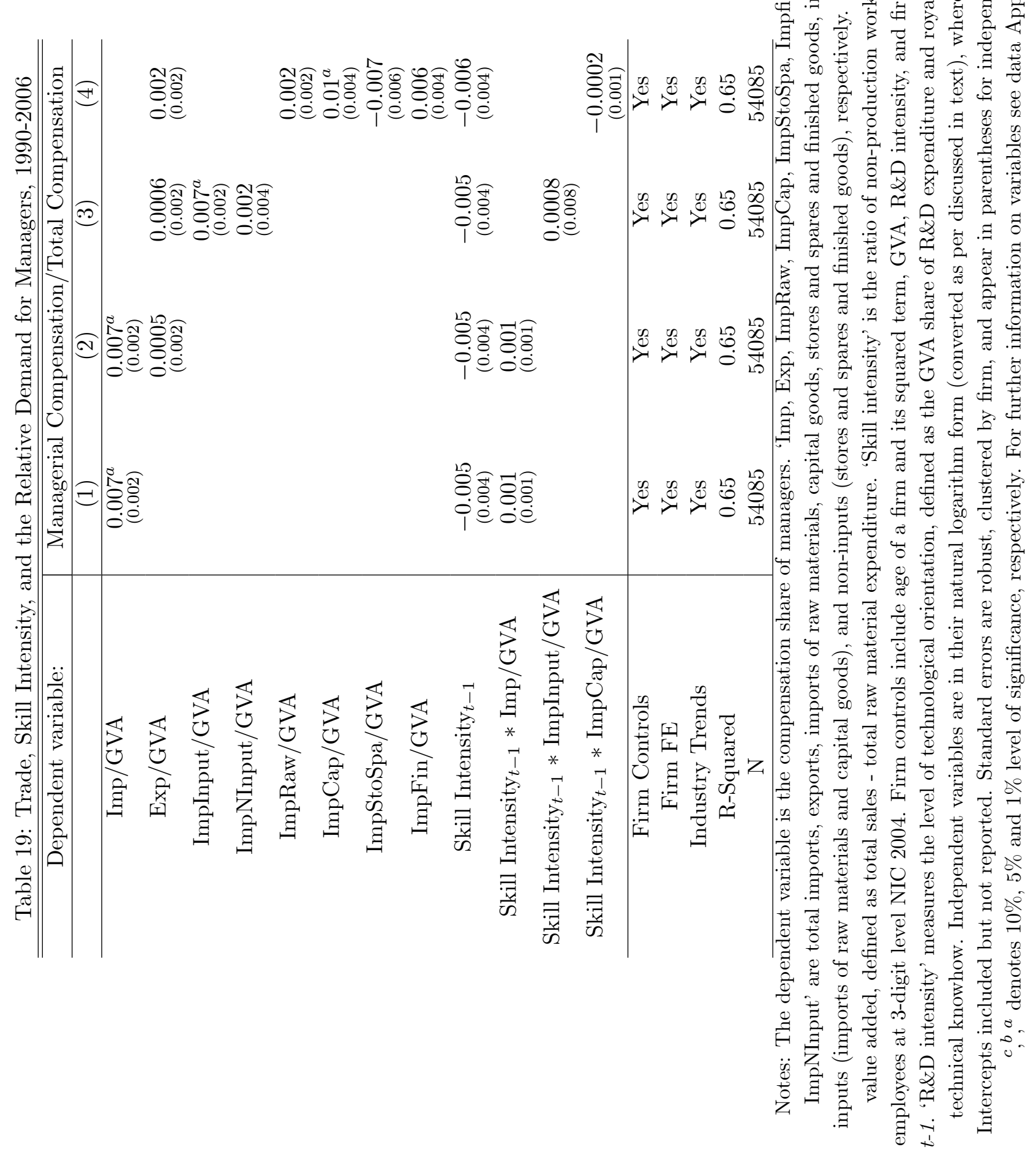


B Figures 


\section{Relative Demand for Managers: Importers vs. Non-Importers, Size Groups Indian Manufacturing Firms: 1990-2006}
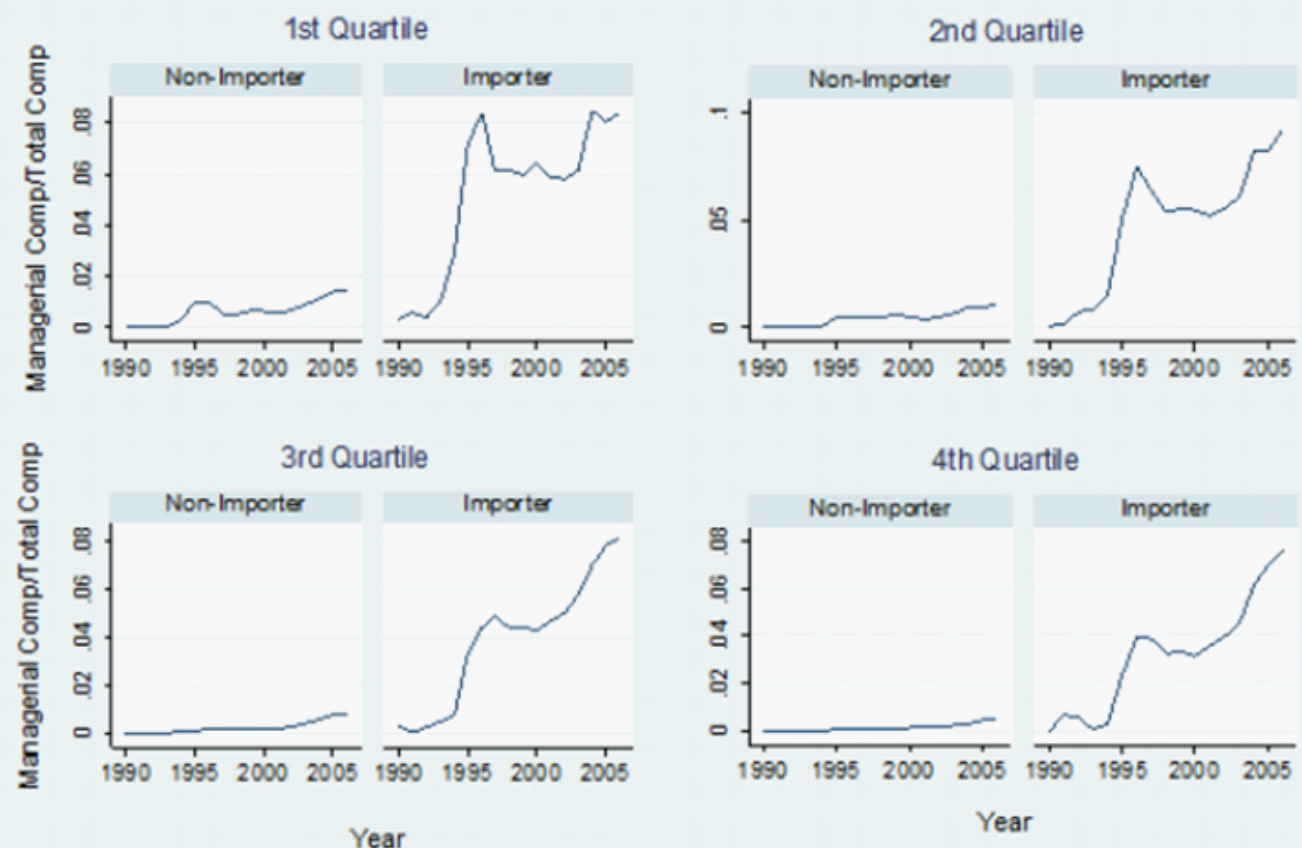

Figure A1: Relative Demand for Managers, Importers and Non-Importers, by Size Quartiles, 1990-2006

Notes: Figure presents the average compensation share of managers for importing and non-importing firms, divided to size quartiles. Size quartiles are defined according to the GVA of a firm (1st [4th] quarter representing the firms with the least [highest] GVA). The period covered is 1990-2006. 


\section{Data}

We use an annual-based panel of Indian firms that covers 8,000 firms, across 108 (4-digit level) industries within the manufacturing sector, over the period of 1990-2006 (with the exception of specific cases, where specified so). Unless otherwise specified, variables are based on data from the PROWESS database of the Centre for Monitoring Indian Economy (CMIE). All monetary-based variables are measured in millions of Rupees, deflated to 2005 using the industry-specific Wholesale Price Index (derived from Allcott, Collard-Wexler, and O'Connell (2016)). All industry-level cases are based on the 2004 National Industrial Classification (NIC).

\section{Variable definitions}

Mcomp/Tcomp: The share of managerial compensation in total labor compensation; compensation defined as the sum of all salaries, and additional bonuses.

Imp/GVA: Share of total imports in Gross Value Added.

ImpRaw/GVA: Share of raw material imports in Gross Value Added.

ImpCap/GVA: Share of capital imports in Gross Value Added.

ImpSto/GVA: Share of stores and spares imports in Gross Value Added.

ImpFin/GVA: Share of final goods imports in Gross Value Added.

Exp/GVA: Share of total exports in Gross Value Added.

GVA: Gross Value Added; defined as the difference between total sales and expenditures on raw materials.

Age: Age of a firm in years.

$R E D$ intensity: Share of $\mathrm{R} \& \mathrm{D}$ expenditure and royalty payments for technical knowhow in Gross Value Added.

Assets: Total firm assets.

Productivity: Firm TFP computed using the Levinsohn and Petrin (2003) methodology.

Input/Output tariffs: HS 6-digit level output tariff data are derived from the TRAINS-WITS tariff database. We use India's input-output matrix for 1993-1994 to construct input tariffs, $\tau_{j, t}^{\text {input }}$, as follows: $\tau_{j, t}^{\text {input }}=\sum_{k} a_{k, j} \tau_{k, t}^{\text {output }}$, where $\tau_{k, t}^{\text {output }}$ is the tariff on industry $k$ at time $t$, and $a_{k, j}$ is the share of industry $k$ in the value of industry $j$. We concord both the input and output tariffs to the 4-digit NIC 2004 level using the Debroy and Santhanam (1993) concordance table.

Export tariffs: We use the HS 6-digit level bilateral tariffs, derived from the TRAINS-WITS database, that are reported under the cases that India is listed as an exporter. The tariffs of each industry were averaged over all trade partners, with the weight for each partner being its share in the Indian exports of that industry in 1990, calculated using data from the UN-COMTRADE database. Formally, we compute export tariffs, $\tau_{j, t}^{\exp o r t}$, as follows: $\tau_{j, t}^{\exp o r t}=\sum_{m} a_{m, j} \tau_{m, j, t}$, where $\tau_{m, j, t}$ is the tariff on industry $j$ at time $t$ for importer $m$, and $a_{m, j}$ is the share of Indian exports (out of its total exports in industry $j$ ) to importer $m$ in 1990. We concord the export tariffs to the 4-digit NIC 2004 level using the Debroy and Santhanam (1993) concordance table.

Famliy share: The firm's ownership share of Hindu undivided families, averaged over 2007-2009. A Hindu undivided family is one that consists of all persons lineally descendent from a common ancestor. The main indicator used in the analysis is a binary index that takes the value 1 if the firm has a positive level of ownership by Hindu undivided families.

Cap/GVA: Share of total capital employed in Gross Value Added. Capital includes equipment and structures.

Skill intensity: The 3-digit NIC 2004 level ratio of non-production workers to all workers, obtained from the Indian Annual Survey of Industries (2001-2006) and from Ghosh (2014) (19902000).

Management technology: The 2-digit NIC 2004 level management quality score in 2004. The score is obtained from Bloom and Van Reenen (2010) in 3-digit SIC classification, which was 
mapped to the 2-digit HS level and thereafter to 2-digit NIC 2004 via the Debroy and Santhanam (1993) concordance table. The score is between 1 and 5 , with 5 denoting the highest quality.

Labor regulation: State-level labor regulation index in 1990. The index is derived from Aghion, Burgess, Redding, and Zilibotti (2008) and is based on the state-level index constructed in Besley and Burgess (2004). The index ranges from -2 to 4, with -2 (4) denoting labor regulations that are pro-employer (employee); it excludes the following states: Delhi, Himachal Pradesh, Manipur, Meghalaya, and Nagaland.

Executives/Directors/Non-managers compensation/wages/bonuses: Total compensation, wages, or bonuses of executives, directors, or non-managers. Compensation is defined as the sum of wages and bonuses. Executives are the top management with executive powers, directors are the midranked managers with no executive powers, and non-managers are workers who do not manage others.

Executives: The number of executive managers.

ChinaImp/IndiaImp: Share of Chinese-sourced imports in Indian imports. HS 6-digit import data are obtained from the UN-COMTRADE database, and matched to the 4-digit NIC 2004 level using the Debroy and Santhanam (1993) concordance table.

\section{Derivations for the Analytical Framework}

Considering the setting described in the main text, variable costs are given by $c=w_{m} \cdot m+w_{n} \cdot n$; $w_{m}$ and $w_{n}$ being the wage rates of managers and non-managers, respectively. Firms operate in a competitive industry, where factor prices are set accordingly. If $m$ and $n$ are the argmin of costs, then $c$ is the cost function. The logarithm of $c$ can be approximated by a translog cost function:

$$
\begin{aligned}
\ln (c)= & \alpha_{m} \ln \left(w_{m}\right)+\alpha_{n} \ln \left(w_{n}\right)+\alpha_{M} \ln (M)+\alpha_{y} \ln (y)+ \\
& \frac{1}{2}\left[\beta_{m m} \ln \left(w_{m}\right)^{2}+\beta_{m n} \ln \left(w_{m}\right) \ln \left(w_{n}\right)+\beta_{n m} \ln \left(w_{n}\right) \ln \left(w_{m}\right)+\beta_{n n} \ln \left(w_{n}\right)^{2}+\right. \\
& \left.\beta_{M M} \ln (M)^{2}+\beta_{y y} \ln (y)^{2}\right]+\gamma_{m M} \ln \left(w_{m}\right) \ln (M)+\gamma_{m y} \ln \left(w_{m}\right) \ln (y)+ \\
& \gamma_{n M} \ln \left(w_{n}\right) \ln (M)+\gamma_{n y} \ln \left(w_{n}\right) \ln (y)+\gamma_{M y} \ln (M) \ln (y),
\end{aligned}
$$

where $y$ is output. Symmetry implies $\beta_{m n}=\beta_{n m}$. By Shephard's lemma, $\partial c / \partial w_{m}=m$, so that the cost share of managers is:

$$
S \equiv \frac{w_{m} m}{c}=\frac{\partial \ln (c)}{\partial \ln \left(w_{m}\right)}=\frac{\partial c}{\partial w_{m}} \frac{w_{m}}{c}
$$

Using this in the translog we get:

$$
S=\alpha_{m}+\beta_{m m} \ln \left(w_{m}\right)+\beta_{m n} \ln \left(w_{n}\right)+\gamma_{m M} \ln (M)+\gamma_{m y} \ln (y) .
$$

By linear homogeneity of cost with respect to prices, cost shares are homogenous of degree zero. Therefore $\beta_{m m}+\beta_{m n}=0$. By linear homogeneity of the production function we have $\gamma_{m M}+\gamma_{m y}=$ 0 ; increasing all inputs by same factor increases output by same factor, but this should not affect the cost share. Using these two properties gives Equation (1).

\section{E Endogeneity of Input Tariffs to Managers' Compensation}

We test the conjecture that input-trade liberalization may be affected by past levels of managers' compensation at the industry level. This may be a potential route of endogeneity because, for 
instance, managers in industries that enable them to extract a relatively larger share of the profits may have a greater incentive to influence trade policies implemented by the Indian government. To test this, we follow the baseline specification (outlined in the text) to estimate the following model:

$$
\operatorname{Tar}_{j, t}=\alpha+\beta(C O M P)_{j, t-n}+\gamma \mathbf{X}_{i, t-1}+\delta_{i}+\eta_{t}+(\text { Ind } * \text { Trend })_{j}+\epsilon_{i, t} .
$$

Notation is consistent with that described in the text, with the exception of Tar, COMP, and $n$. Specifically, Tar $\in$ (InpTar,,OutTar), where InpTar (OutTar) are input (output) tariffs. $C O M P \in\left(\frac{M c o m p}{T \text { comp }}\right.$,ExecWage $)$, where $\frac{M \text { comp }}{T \text { comp }}$ is the compensation share of managers, and ExecWage is the per-executive wage. Note that each of the compensation and tariff measures presents the industry $(j)$ average at the 4-digit NIC 2004 level. Last, $n \in[1,3]$. Hence, we test the association of either of the two compensation measures, each being in one to three year lags, with the contemporaneous level of either output or input tariffs.

Results appear in Appendix Tables 14 and 15. The former (latter) examines the case of input (output) tariffs. In each, Columns (1)-(3) ((4)-(6)) test the cases of $\frac{\text { Mcomp }}{\text { Tcomp }}$ (ExecWage), under each of the three lags. In all cases the estimated $\beta$ indicates that there is no apparent association between past industry-level compensation measures and trade liberalization, further supporting the exogenous nature of the trade shocks examined.

\section{F Governance Structure and the Relative Demand for Managers}

We examine two additional standard (time-varying) measures of governance structure, derived from PROWESS. The first (Indep) looks into the number of independent directors in the board of directors, normalized by GVA. The second $(B O D)$ captures the size of the board of directors, normalized by GVA. Notably, only a relatively small fraction of the firms in our sample report these measures, hence the sample size in this analysis is significantly restricted.

We estimate two specifications with these measures; both follow the baseline model outlined in the text. The first estimates the heterogeneous effects of input-trade liberalization on the relative compensation of managers across governance levels. The second tests whether input-trade liberalization affects the extent of the governance structure.

Hence, for the first case we estimate the following model:

$$
\begin{aligned}
\frac{M \operatorname{comp}}{\operatorname{Tcomp}}_{i, t}=\alpha+\beta \ln (\operatorname{InpTar})_{j, t-1}+\phi G_{i, t-1}+\theta \ln (\operatorname{InpTar} * G)_{i, t-1} & \\
& +\gamma \mathbf{X}_{i, t-1}+\delta_{i}+\eta_{t}+(\text { Ind } * \text { Trend })_{j}+\epsilon_{i, t} .
\end{aligned}
$$

The second case is estimated via the following model:

$$
G_{i, t}=\alpha+\beta \ln (\text { InpTar })_{j, t-1}+\gamma \mathbf{X}_{i, t-1}+\delta_{i}+\eta_{t}+(\text { Ind } * \text { Trend })_{j}+\epsilon_{i, t} .
$$

Notation is consistent with that described in the text, with the exception of $G$. Specifically, $G \in($ Indep, BOD) where Indep and $B O D$ are as described above. Results appear in Appendix Table 17. Columns (1) and (2) follow the first specification, whereas Columns (3) and (4) follow the second. The estimates in all cases suggest that input-trade liberalization: i) does not lead to heterogeneous effects on the compensation share of managers across levels of these two measures; ii) does not affect the level of these two measures. 


\section{G Labor Market Regulations and the Relative Demand for Man- agers}

We examine an additional cross-sectional state-level measure of labor market regulations, derived from Gupta, Hasan, and Kumar (2009). In effect, this measure is based on the one constructed by Besley and Burgess (2004), employed in the text, yet it incorporates further revisions of it made in Bhattacharjea (2006), and the OECD (2007). It takes the values of $-1,0$, or 1 . The first/second/third represents inflexible (pro-employer)/neutral/flexible (pro-employee) labor market regulations. Similar to the index of Besley and Burgess (2004), the following states are excluded: Delhi, Himachal Pradesh, Manipur, Meghalaya, and Nagaland.

Hence, we estimate variates of the following model:

$$
\begin{aligned}
\frac{M c o m p}{T c o m p}_{i, t}=\alpha+\beta \ln (\text { InpTar })_{j, t-1}+\phi \text { Labor }_{i}+ & \theta \ln (\text { InpTar } * \text { Labor })_{i, t-1} \\
& +\gamma \mathbf{X}_{i, t-1}+\delta_{i}+\eta_{t}+(\text { Ind } * \text { Trend })_{j}+\epsilon_{i, t} .
\end{aligned}
$$

Notation is similar to that described in the text, with Labor representing the labor market regulations index described above, interacted with the firms' state-location. Notice that its average effect is absorbed by $\delta$, given that it has no time variation. Results appear in Appendix Table 18. Columns (1) and (2), follow Columns (1) and (2) of Table 8. The positive and significant $\theta \mathrm{s}$ indicate that the patterns observed under this additional measure are similar to those estimated with the baseline index described in the text: input-trade liberalization affects the compensation share of managers more strongly in states with laxer, pro-worker labor market regulations.

\section{H Skill Intensity and Trade}

To better observe the role of skill intensity in our analysis, we replicate Table 3, adding our proxy for skill intensity (in $t-1$ ) as a regressor in each of the regressions, with its interaction with the variable of interest in each case (either imports, imported inputs, or imported capital goods). The details of the skill intensity measure are outlined in the main text (Section 3.3.9), as well as in the Appendix. Additional differences from Table 3 include: (i) the exclusion of its Column 2, as in the current case it is redundant to Table 3's Column 3 in which both imports and exports are included concurrently; (ii) the exclusion of industry-year fixed effects, which otherwise would absorb the skill intensity measure (given it is at the industry-level), and the inclusion of industry-specific time trends instead.

The results are presented in Table 19. Columns 1-4 replicate Columns 1, 3, 4, and 5 of Table 3, respectively, with the above mentioned modifications. As observed, the key results discussed in Section 3.2 remain to hold in sign, significance, and magnitude in each of the cases, despite controlling for skill intensity and its interactions. In addition, the latter indicate that there is no apparent differential effect across industries' benchmark skill intensity levels, similar to the patterns observed in Section 3.3.9. 